\title{
Modelling Physiological and Pharmacological Control on Cell Proliferation to Optimise Cancer Treatments
}

\author{
J. Clairambault ${ }^{1}$ \\ INRIA Paris-Rocquencourt, BANG project-team, BP 105, F78153 Le Chesnay Cedex
}

\begin{abstract}
This review aims at presenting a synoptic, if not exhaustive, point of view on some of the problems encountered by biologists and physicians who deal with natural cell proliferation and disruptions of its physiological control in cancer disease. It also aims at suggesting how mathematicians are naturally challenged by these questions and how they might help, not only biologists to deal theoretically with biological complexity, but also physicians to optimise therapeutics, on which last point the focus will be set here. To this purpose, mathematical modelling should represent proliferating cell population dynamics with natural built-in control targets (which implies modelling the cell division cycle), together with the distribution of drugs in the organism and their molecular actions on different targets at the cell level on proliferation, i.e., molecular pharmacokinetics-pharmacodynamics of antiproliferative drugs. This should make possible optimal control of drug delivery with constraints to be determined according to the main pharmacological issues encountered in the clinic: unwanted toxic side-effects, occurrence of drug resistance. Mathematical modelling should also take into account physiological determinants of cell and tissue proliferation, such as intervention of the immune system, circadian control on cell cycle checkpoint proteins, and activity of intracellular drug processing enzymes together with individual variations in the activities of these proteins (genetic polymorphism). Taking these points into account will add to the rich scenery of normal or disrupted cell and tissue regulations, and their corrections by drugs, a natural environmental, whole body physiological, frame. It is necessary indeed to consider such a framework if one wants to eventually be actually helpful to clinicians who routinely treat by combinations of drugs living Humans with their complex whole body regulations, often dependent on genotypic variations, and not isolated cells or tissues.
\end{abstract}

Key words: cell proliferation, population dynamics, physiologically structured partial differential equations, pharmacological control, pharmacokinetics-pharmacodynamics, physiological modelling, cancer treatments, therapeutic optimisation, individualised medicine

AMS subject classification: 92-02, 92B05

\footnotetext{
${ }^{1}$ E-mail: jean.clairambault@inria.fr
} 


\section{Biological common knowledge on cancer}

This section shortly presents the general scenery of cancer evolution and features that must be included in models designed to describe and control it, bearing in mind a more descriptive (physicist's) than a therapeutic (physician's) point of view, only to reverse this perspective in the following sections, in which will be stressed the interest of modelling from the point of view of control, at least if one wants to design models for therapeutic applications. This biological section will be only a short sketch, if one considers that on this subject many books have already been written, e.g. $[24,78,96,97,223]$.

\subsection{Cancer: a challenging public health problem}

Cardiovascular diseases and cancer are by far the two major causes of death by disease, worldwide, cancer being an outdistanced second [271]. But, whereas in developed countries at least, numerous successes have been obtained in the treatment of cardiovascular diseases, dividing by 2 the number of deaths of cardiovascular origin in the last 30 years $[13,134]$, the same is far from being true for cancer. In fact, in at least 2 developed countries where rather long-range data are available, France and the USA, cancer has become the first cause of deaths, before cardiovascular diseases [13, 134]. This does not necessarily imply that therapeutic progresses in the fight against cancer are at a standstill; it may also be the case that new causes, or new forms of cancer have emerged, or even more likely that increase in life expectancy due to better general healthcare makes genetic mutation events and resulting cancer diseases more probable. Whatever the reason, cancer is either the second or the first cause of death by disease, according to the availability of healthcare, and this is a challenge to physicians, and further, to health regulation authorities. Can mathematics help fight cancer? Or, to put it in a sharper way, can mathematical analysis methods, can theorems prove some utility to cure cancer? I will try to show how one can answer positively these questions.

\subsection{Cancer: a complex disease with a multiscale development}

Cancer is an evolutionary disease, and it is not necessarily the disease of one cell generating a tumour clone, but rather of a population of cells -which is not the plain sum of its individual cellsthat shows inefficient control of its proliferation. It manifests itself physically at the macroscopic level by localised tumour growth and remote invasion, but also in a less visible way by provoking the emission of chemical signals by tumour cells or their surrounding stroma, which perturbs the physiological controls exerted on cell replication. These controls may be local, at the subcellular level, regional, at the tissue level, and even global, by central nervous system and hormonal signalling, and by involvement of the immune system.

This multiscale perspective has been recently developed in various papers, among which $[6,12$, 187], at least from the subcellular to the tissue level. The whole organism level of control is less frequently taken into account; for a different view involving the influence exerted by the circadian system on cell and tissue proliferation, see [51]. 


\subsection{Carcinogenesis}

In an often cited review article [122], Hanahan and Weinberg identified six main disrupted control mechanisms that eventually lead to the development of malignant tumours (evading apoptosis, independence from growth and antigrowth signals, sustained angiogenesis, tissue invasion and development of metastases), and these mechanisms are common, with different degrees, to all tumours at a late stage of development. In a classical [81] and in a more recent article [103], a sequential mechanism setting an evolutionary perspective between these, and other, mechanisms, has been proposed. A common feature that is invoked to explain the emergence of these disruptions is "genomic instability", a way to say that the main caretakers of genome integrity, among which the "guardian of the genome" (otherwise said, the main tumour suppressor gene), protein p53 [50, $107,161,264]$, are so inhibited or mutated that they have become inefficient in their ward mission on cell replication [232].

But studying disruptions of proliferation should not be restricted to observations at the level of a single cell, since cancer cells strongly interact with surrounding stromal cells [86, 122]. Moreover, metabolic conditions (in particular acidosis $[102,103]$ ) for tumour development, and conversely inhibition of normal cell survival and replication strongly depend on the tumour microenvironment, to such extent that it has been reported that tumour development may be reversed and even annihilated by changing its environmental metabolism [160].

\subsubsection{Gene mutations}

Gene mutation by replication errors is the phenomenon most often invoked to account for evolution of cells towards malignancy. If one caretaker of the genome commits a mistake on checking its integrity at one of the checkpoints of the cell division cycle (mainly through ATM and ATR kinases $[123,244]$ ), with cell cycle arrest by p53 at transitions between $G_{1}$ and $S$ phases, and between $G_{2}$ and $M$ phases [136, 191, 193], then if this mistake is not subsequently corrected by DNA repair mechanisms [274], more errors can occur, proliferation can become less and less controlled, and a cancer cell population can thrive.

Knudson's two-hit hypothesis [148] states that one single mutation is not enough to give rise to a cancer cell, likely because it is located on only one chromosome, and the other allele compensates when the gene is recessive. But a hit at this other allele, a very rare event that becomes more probable when errors in replication are frequent, may yield a non recoverable mutated genome, that will eventually produce a cancer cell.

DNA polymerases have been proposed to be error-prone in cell replication and hence responsible for mutations when the involved cell populations have been submitted to a stress (e.g., starvation) during their stay in $G_{0}$ phase [41]; at least, this has been observed in bacteria [146], leading to their better adaptation to a changing environment, and one could imagine that such explanation for mutagenesis could be transposable to mammalian cells.

Mutations of protein p53 are the most often found mutations in all cancers [128, 172]: the "guardian of the genome" being incapable to fulfill its mission (and send cells with unproper genetic material to apoptosis), more and more mutated cells appear and may develop into a tumoral formation. Genome instability, i.e., the capacity for a cell to develop mutations in its genome when 
it replicates, is thus often the consequence of the incapacity of mutated p53 to accurately check genome integrity at cell cycle checkpoints.

\subsubsection{Disputes on the origin of cancer: clonal or not clonal?}

Gene mutations are presently the most widely admitted cause of cancer. But a challenging explanation exists, that relies on the denial of the unicellular (or monoclonal) origin of the disease, expressed in the provocative statement: "one renegade cell: how cancer begins" (R.A. Weinberg [268], quoted in [248]). Rather, A. Soto and C. Sonnenschein, in a series of articles $[188,248,249,247,250]$ advocate the preeminence of the surrounding stroma in carcinogenesis, opposing their tissue organisation field theory (non clonal origin of cancer) to the classical somatic mutation theory (clonal origin). A close view is also discussed, with many references, in [31].

Being in no position to take part in this theoretical biology dispute, I will only remark that the tissue organization field theory seems to be consistent with evolutionary theories transposing Darwinism to the cellular field $[155,156]$ to yield an ontophylogenetic point of view [157] that is in accordance with the fact that the same mechanisms (in particular "sculpture of the living" by apoptosis [10], see also [195, 196] on netrin-1 DCC receptors) are often present in both carcinogenesis and organogenesis, the former, contrasting with the latter, being of course out of local tissue control. Can these opposed views be reconciled? It should be to no avail, advocate Soto and Sonnenschein [248]; yet from a modelling point of view, it could be quite consistent with recent unifying mathematical theories that merge individual stochastic processes into physiologically structured partial differential equation models [25, 45, 104, 105, 218], thus authorising a natural multiscale point of view on carcinogenesis (gene, molecule, cell and tissue). In short, a unifying view may consist in seeing cancer more as a tissue disease rather than a single cell disease: the "renegade cell", if it exists, may develop into a robust cell clone only if favourable microenvironmental conditions are present.

\subsubsection{Cancer as an evolutionary dynamic process; stem cells}

Such common biological observations, based on disease-initiating events that may be of stochastic nature, enable to consider cancer as an evolutionary stochastic process, so that probabilistic models have been used to describe cell and tissue evolution towards invasive cancer. Such an observation has also been mentioned already about carcinogenesis: there exists a temporal hierarchy (i.e., an order in evolution) between features of cancer cells that lead towards malignancy [12, 81, 103], with or without stress-induced $G_{0}$ phase mutagenesis. Another feature that can be represented in such models is the differentiation vs. proliferation alternative that is common to all cells undergoing mitosis, a feature illustrated in particular in classical papers on intestinal crypts [221, 222]. The relevance of a probabilistic perspective is also naturally supported by the fact that the healthy cell populations that most commonly evolve towards malignancy are those that are physiologically submitted to fast renewal, i.e., mainly epithelial cells of the gastro-intestinal tract or of the broncho-pulmonary airways, and cells of the haematopoietic bone marrow, for which daily production is so high, in order to make up for natural loss (into the intestinal lumen, into the general 
blood circulation), that errors in gene transcription are also naturally more frequent than in slowly renewing tissues.

This probabilistic point of view on the expansion of a cancer clone has been developed at the level of stem cells [68, 69], in particular in the case of Chronic Myelogenous Leukaemia (CML) [215]. Stem cells are the pluripotential undifferentiated cells that are found in all renewing tissues, in very small numbers, from which proliferating cell populations arise [266]. They have been particularly studied in the intestinal crypt [221, 222] for mucosa proliferation, and in the haematopoietic system $[68,69,70,72,139,140,173,192,233]$. Stem cells are an object of active research, not only for cancer, but also for other diseases in which tissue reconstruction by young cells is needed.

\subsection{Physiological controls on cell proliferation that are disrupted in cancer}

\subsubsection{Robustness or fragility of intracellular signalling pathways}

The disrupted mechanisms pointed out in $[81,122]$ are firstly described from the point of view of cell physiology. From the point of view of intracellular signalling involving these same mechanisms [122, 149, 150,151], one can search for the molecular pathways that are no longer under control, and whether or not the signalling network they constitute has a structure that renders cancer cells robust with respect to usual physiological control inputs, otherwise said relatively insensitive to them. This point of view has been developed by H. Kitano in a series of articles [143, 144, 145], where he proposes that such a robust network must have a "bowtie architecture", with a limited number of hubs as in an airplane company network. This robustness has a fragility counterpart: if all hubs are destroyed simultaneously, then the network is down, suggesting that such fragility targets should be used as a perspective in anticancer drug development. This happens to be the case with Chronic Myelogenous Leukaemia (CML), where the chimeric protein BCR-ABL is entirely responsible for the proliferation advantage of leukaemic cells [26, 180]. A drug that blocks very specifically its activity, Imatinib, has been available since the last ten years, with no side effects $[75,76]$; since then, the prognosis of the disease has radically changed. Unfortunately, this favourable situation: single target, specific inhibitor with no toxicity is not so frequent, and this success story has not found its equivalent in other cancers so far, but this "robustness vs. fragility" guideline may inspire research in drug discovery in a systems biology framework (investigation of intracellular interaction networks involved in proliferation).

\subsubsection{The cell division cycle}

One cell becomes two at mitosis: all tissue proliferation relies on this mechanism. Before mitosis ( $M$ phase), cells undergoing replication pass through phases $G_{1}, S$, and $G_{2}$. During $S$ phase, the cell duplicates its DNA, the other two phases being dedicated to growth and preparation of the next phase by synthesizing material, of mainly proteic nature (cyclins in all phases, and specific proteins, such as tubulin in $G_{2}$ ). This progression through the cell division cycle is controlled at so-called checkpoints [136], located mainly at $G_{1} / S$ and $G_{2} / M$ phase transitions, where the cell cycle may be arrested and the cell undergo DNA repair or apoptosis (cell death), in case of 
DNA damage. DNA damage detection is performed by sensor proteins (ATM), that trigger protein p53 ("guardian of the genome"), that will itself arrest the cell cycle at $G_{1} / S$ or $G_{2} / M$ transitions, and either induce successful DNA repair by specific enzymes [274, 149], or launch apoptosis (see below). The progression in the cell cycle is also controlled in cell death in all phases, and in speed, at least inside $G_{1}$ phase [204].

\subsubsection{Growth and antigrowth signals}

The progression in the cell division cycle, especially in $G_{1}$ phase, is enhanced or inhibited by external growth and antigrowth factors $[122,193]$, that bind to cell membrane receptors, whence subsequent intracellular signalling launches or stops the synthesis of proteins that are necessary for the cell to progress in $G_{1}$ phase. Blockade of these receptors by specific molecules, e.g., epidermal growth factor (EGF) receptor antagonists, is a therapeutic means that is common nowadays in the clinic [198].

\subsubsection{Apoptosis}

Apoptosis, or controlled cell death, is the process by which cells that are stopped in their progression in the cell division cycle and have been recognised as improper to undergo differentiation, or stay in a quiescent state until growth conditions in $G_{1}$ are more favourable, undergo clean destruction, i.e. without releasing cytoplasmic factors that would be toxic for surrounding cells (which is on the contrary the case with necrosis). It is a rather fast process, involving a chain of reactions due mainly to proteins called caspases, ending up in cleavage and digestion of cell remnants. It has been studied extensively, in particular in [177, 178]. Apoptosis can occur at all cell phases, but more especially at $G_{1} / S$ and $G_{2} / M$ transitions, under the dependence of protein p53, that, upon triggering by messages from sensor proteins that check genome integrity, can launch the apoptosis cascade [136, 204]. To remain alive, some cells must see specific receptors on their membrane permanently occupied by special molecules (e.g., Netrin, binding to the DCC receptor $[195,196]$ ), otherwise apotosis is launched.

\subsubsection{Cell adhesion: cell-cell and extracellular matrix}

In the same way, to remain alive, normal cells must permanently receive signals from other akin cells, or attach to the basal membrane for epithelial cells, or to the extracellular matrix, a natural weft constituted of different sugar molecules and fibres of collagen and elastin. The binding of cells to the extracellular matrix is due to fibronectins and regulated in particular by integrins [179]. Cancer cells have the power to remain alive without need of these anchoring signals, which enables them to move freely and invade surrounding tisues (in particular by digesting the extracellular matrix by metalloproteases) and further, by intravasation and extravasation in lymphatic and blood vessels, to create remote metastases. 


\subsubsection{Angiogenesis}

Tumours need supplies in oxygen and nutrients brought by the blood circulation to thrive. When the local development of a cancer gives rise to a spheroid tumour, cells proliferate on the external spherical rim, that surrounds a bowl constituted of quiescent (non proliferating) cells, that contains in its core necrotic cells, choked by isolation from oxygen supplies. This avascular stage of tumour development, with no blood vessels irrigating the tumour, yields spheroids of 1-2 mm of diameter, not more. But from this still non localised and stagnant state, advanced tumours progress, to emit a vascular endothelial growth factor (VEGF) that stimulates neoangiogenesis, i.e., formation of new vessels sprouting from the neighbouring vascular network and penetrating inside the tumour to feed its cells. Then the tumour has in principle no limit to its growth, except biomechanical constraints. A recent review on angiogenesis can be found in [223]

\subsubsection{The immune system}

Cancer cells are usually immunogenic, i.e., the immune system normally recognises them as foes and sends lymphocytes and macrophages to destroy them. But cancer cells may avoid recognition by immune cells by fostering, through genome instability and facilities to develop adapted mutant cells, the outgrowth of low immunogenic tumour cell clones that escape immunosurveillance [280].

\subsubsection{Perturbations of circadian clocks: resulting in cell population desynchronisation?}

Cell proliferation in tissues, normal or diseased, is influenced at the level of individual cell division cycle controls (in particular $G_{1} / S$ and $G_{2} / M$ transitions, e.g. through p53, but also cyclin synthesis, apoptosis determinants) by inputs from local circadian clocks [32, 229]. One clear molecular connection between the circadian clock and the cell division cycle has been established in [194, 239, 277], by showing that kinase Wee1, that inhibits the synthesis of the $C y c l i n B-C d k 1$ complex, controlling $G_{2} / M$ transition, is itself controlled by the circadian clock gene Bmal1. Since normal cell populations seem rather well synchronised with respect to phases of the cell division (undergoing e.g., $S$ phase, more or less all at the same time) and show circadian rhythm in this synchronisation [246], rhythms that are harder to find in tumours [118], one can hypothesize that such synchronisation is due to circadian clock inputs, and that cancer cells have lost this synchrony -that could be necessary to ensure normal control of cell proliferation- by escaping normal control on their division cycle by circadian inputs. To support this hypothesis, one can note that transgenic mice lacking an essential gene of the clock, Per2, are more prone to develop cancers [98, 99], secondly that disrupted circadian rhythms result in faster tumour growth in tumour-bearing mice $[84,85]$, and thirdly that tumour-bearing patients who show low amplitude circadian rhythms are known to be of bad prognosis. Since these patients in parallel exhibit high levels of circulating tumour-emitted cytokines [231], a question arises: do tumours enhance their development by disrupting circadian clocks, and hence desynchronising their division cycle, resulting in higher proliferation rate? To support this hypothesis, tumour-emitted cytokines playing the disrupting role on the central circadian pacemaker, one can note that a disrupting role of 
the cytokine $T G F \alpha$ on the central circadian pacemaker of the suprachiasmatic nuclei has been experimentally shown in mice [154].

\subsection{Main weapon in the hands of physicians fighting cancer: drugs}

\subsubsection{Cytotoxic and cytostatic drugs. Combinations of drugs}

Classically, one distinguishes between cytotoxic drugs, that kill cancer cells, and cytostatic drugs, that slow down and stop tumour growth, without necessarily killing cells. Cytotoxic drugs act either by directly damaging the DNA, or by blocking enzymatic systems (e.g. thymidylate synthase for cells in $S$ phase, with 5-fluorouracil) or cell structures that are essential for cell division (e.g., the mitotic spindle for cells in $M$ phase with vinca alkaloids), resulting in non viable cells that are subsequently eliminated. Cytostatic drugs may for instance block epidermal growth factor (EGF) receptors on the external membrane, thus inhibiting cell growth without launching apoptosis. But one same drug may have multiple targets (e.g. tyrosine kinase inhibitors), and be cytostatic at a given concentration, and cytotoxic at another [127], so that this distinction is not clear enough to allow classification between different drugs.

An important consideration is that different drugs acting on different cell targets often show complementary (synergistic) effects by their combinations. Such associations of drugs are the most frequent therapeutic strategies used in the clinic of cancer nowadays, often with remarkable successful protocols associating 3 or 4 different drugs.

\subsubsection{Complementary therapies}

Drugs acting on the cell microenvironment may help the action of other drugs, without being sufficient by themselves. This is the case for antiangiogenic drugs, in use in the clinic, that oppose tumour neoangiogenesis, for instance by blocking the receptors to tumour-emitted chemo-attractants on the membrane of endothelial cells. Other drugs have been tried to oppose the metalloproteases (MMP), or matrix digesting enzymes (MMP Inhibitors, not very successful so far in the clinic), that invasive cancer cells emit to progress through the extracellular matrix network. Another interesting idea, not really exploited so far in therapies, would be to enhance the local tissue $\mathrm{pH}$, since it has been shown that tumour cells have a proliferative advantage over normal cells due to the fact that their metabolism, more prone to anaerobic glycolysis, works well in lower $\mathrm{pH}$ conditions (rather than physiological 7.4: 7.1, say), at which normal cells die [101, 102, 103].

\subsubsection{Other than drugs: surgery, radiotherapy, immunotherapy}

Although surgery for solid tumours, or bone marrow engraftment in haematology, are, when they are successful, the most radical ways of curing cancer, they are of limited use and not without life-threatening risk: e.g., difficulties linked to multiple liver metastases or inaccessible brain tumours, difficulties to find a compatible bone marrow donor, and with the usual risks that are linked to surgical intervention, and graft versus host disease in the case of engraftment. Combinations 
of chemotherapy and surgery have proved successful in the treatment of metastatic colorectal cancer [108].

Radiotherapy, accompanied or not by surgery, has been in use for many years, with clinical achievements especially in the case of spatially circumscribed tumours without vital organs in their surroundings. It acts, locally in space, by creating irreversible damage (double strand breaks) to the DNA of cells that receive it [44]. Its specificity against cancer cells is linked to a good localisation of the tumour and may be enhanced by the modern use of heavy particles (hadrontherapy), that yield higher energy transmitted and a better focus on the tumour [240], but need specific equipment.

Immunotherapy, i.e., enhancing the immune response by anticancer vaccines (e.g., made of inactivated cancer cell membrane extracts) is one of the points where cancer research meets immunology, but it has remained at the experimental stage thus far. On the contrary, the participation of the immune response in the success of conventional cancer chemotheray has been in the recent years the object of documented studies [281, 282].

\subsection{Problems encountered in dealing with anticancer drugs}

\subsubsection{Unwanted toxic side effects on healthy cells}

Toxicity to healthy tissues, mainly fast renewing ones, is the main issue of cancer treatments. The most important fast renewing tissues are the intestinal mucosa and the haematopoietic bone marrow, where the normal turnover rate is between 25 and $50 \%$ per day by elimination in the intestinal lumen (figures for mice extracted from [221]) or release in the general circulation (evaluation from various tutorial books on haematopoiesis, based on about $10^{12}$ nucleated cells in the bone marrow and $25.10^{10}$ cells released in blood). It would be in principle possible to kill any number of tumour cells by cytotoxic drugs, if were not present a dose limitation constraint imposed to avoid insulting too heavily healthy tissues. There is always a trade-off between therapeutic efficacy and toxicity, and the window between minimum efficacy and detrimental toxicity (lethal by damage to organs) is at times narrow. Respecting this constraint by time-scheduled intravenous drug delivery regimens is a challenging optimal control problem.

\subsubsection{Resistance to drugs in cancer cells}

Innate or acquired, reversible or not, dose-dependent or not, all sorts of resistances to drugs, with very different mechanisms, can be encountered in cancer cells, and these resistances are another important issue in cancer treatment.

Resistances can be due to modified cell processing metabolism: low drug cell uptake, high levels of glutathione or specific detoxification enzymes [19, 203, 251], enhanced DNA repair enzyme activity [263], but also most often to enhanced activity of so-called ABC transporters, membrane proteins that expel actively (i.e., by consuming ATP) exogenous molecules from the cytoplasm [117, 212, 213, 228]. These ABC transporters are physiologically expressed by normal cells to maintain hermetically closed biological barriers, particularly the intestinal mucosa and the blood-brain barrier, but cancer cells are able to activate their transcription to gain protection 
against anticancer agents when normal cells are not. Moreover, at least one of these transporters (the P-glycoprotein, or P-gp) may be exchanged by trogocytosis (membrane fusion) between tumour cells and special stromal cells (the so-called "hospicells"), to confer acquired resistance to these tumour cells [226]. It is a goal for pharmaceutical companies to develop ABC transporter inhibitors, that can be associated in combined treatments with the drug they are known to expel, and partial success have been obtained toward this aim by drugs such as Verapamil, Ciclosporin and others [129], some of them specific of such blockade, as Zosuquidar, that has proved activity in treated Acute Myelogenous Leukaemia (AML) [256].

The activity of these transporters is known to be induced by drug administration, but little is known of the mechanisms of this induction (proteic synthesis via a nuclear factor sensitive to the drug itself, or to the DNA damage it provokes? activation from an inactive state in the membrane?), which makes modelling of their kinetics a difficult enterprise. But if such induction is acquired by drug exposure, and dose-dependent, then it may be avoided by dose limitation, and this may be considered as a constraint to be respected in drug delivery optimisation.

Another mechanism of resistance that may be acquired thanks to the genomic instability of cancer cells has already been mentioned (see: "Gene mutations"): the mutations of the target. It is for instance the only known mechanism of resistance to Imatinib in Chronic Myelogenous Leukaemia (recent reviews in [38, 224]).

\subsubsection{Genetic polymorphism in drug processing mechanisms}

We are not always equal with respect to reactions to drug exposure because of innate differences in the intracellular drug processing mechanisms, by drug detoxification enzymes (that are often specific of a given drug or family of drugs) and other molecules. This is also true of differences that may be due to inherited mutations of the drug targets, for instance of EGF receptors. Some of us may eliminate very quickly a particular infused drug, and will need high doses, whereas others will endure toxicity effects at very low doses. These mechanisms, and this interindividual variability, are genetically determined. It is then advisable, as much as possible, to individualise treatments according to the genetic constitution of patients with respect to their drug processing systems, in particular enzymatic drug degradation systems, when these systems and their genetic polymorphism are known. Few markers for these genes are known thus far, but the future of oncology should be in addressing more molecular targets than organs, with patient genotyping prior to any treatment $[40,47,201]$. Some biotechnology companies have even recently specialised in so-called "theranostics" (meaning diagnosis for therapeutics), i.e., diagnosing a patient's ability to benefit from a given treatment, according to his or her genetic characteristics, e.g. mutated (or not) EGF receptor and treatment by EGF receptor antagonists, mutated (or not) p53 status [265]. 


\section{Modelling cell proliferation}

\subsection{A great variety of models}

Mathematical models of cancer and healthy tissue growth at different levels, from gene expression to the phenomenological description of macroscopic tumour development, are numerous and rely on almost all components of analysis and probability theory.

\subsubsection{Choosing a model type}

What sort of model should be chosen to represent tumour and healthy cell proliferation: Spatial or not? Physiologically structured or not? Continuous or agent-based? Stochastic or deterministic? Phenomenological or mechanistic? These are some questions to have in mind when designing models, at least cell population ones, intended to help medicine, in particular for cancer therapy.

If anything is known of a geometrical structure of the tissue, and if diffusion phenomena (of cells, of locally produced molecules, or of externally delivered drugs) are at stake, then spatially structured models should be used. This is true of models of tumour invasion, in particular gliomas (brain tumours), that are known to evolve with radial diffusion from a localised point in brain, invading the surrounding tissue within the skull. But often no clear space structure emerges; concentrations of drugs may be taken in first approximation as spatially homogeneous in a given cell compartment; similarly, tumour and healthy cell populations, of different maturation stages, together with vessels, immune cells, possibly acellular necrotic zones, look very mixed up when observed with a microscope, so that space is not always a relevant structure variable for model design in cancer growth.

On the contrary, in such cases of apparently very heterogeneous cell populations, subpopulations may be distinguished by physiological characteristics (and biological staining for their observation), with differences in sensitivity to pharmacological control of their growth, which justifies the use of physiologically structured models that have nothing to do with space. Physiological structure variables may be concentrations in cell cycle determinant proteins, as cyclins, but also lumped variables representing progression in an evolution mechanism, as age, maturation, or the diffusion of a genetic trait in the cell population.

If the populations of cells under consideration are large enough, using continuous models to represent their evolution is fully justified. But precisely this "large enough" limit is not easy to define, and below it, stochastic phenomena may be predominant. On the basis of cellular automata, such "agent-based" (or individual-based) models, describing the evolution of a cell population based on the description of the fate of each individual cell and its relations with its neighbours (binding, repulsion, chemical signal emitting and receiving) may be used.

Stochastic effects, important when few cells are in contact, may also be considered at larger scales of cell numbers; then, averaging random variables yields continuous models. The predictions of the two sorts of models may then be compared with biological observations, to propose conditions under which preference should be given to one or the other. 


\subsubsection{The physicist and the physician: a question of points of view}

It is a rather different problem to represent, on the one hand tissue growth with the idea to describe all phenomena determining hyperplasia, local and later remote invasion of a budding colorectal tumour, and on the other hand cell population dynamics of the same tumour with control targets, in the perspective of using pharmacological means known to inhibit only some of these growth mechanisms, that have been assessed as crucial by oncopharmacologists and clinicians.

This difference of points of view may also be seen as a "physicist versus chemist" difference. Indeed, the physicist's point of view, as described above, is also of interest for radiotherapists, who have access only to the outer structure of tumours, as seen on radiological images. But the "chemist's point of view", that one may characterise as showing relatively little interest for the description of macroscopic tissue growth for itself, and much more for its pharmacological inhibition at the molecular level, is usually also the most widely present way of thinking among physicians, with the likely exception of radiotherapists and pathologists. Oncologists most often deal only with drugs and their effect on cell proliferation, that is appreciated by a variety of clinical signs and biological quantitative measurements, and little if at all on the macroscopic structure of tumours.

\subsubsection{Phenomenological versus mechanistic}

"Phenomena" are usually thought of as what is manifest to our eyes, whereas mechanisms are the hidden explanation of how things occur or work. According to Anaxagoras, "Phenomena are the visible of invisible things" ("Opsis ton adelon ta phainomena", which may also be translated as "the phenomena are the sight of what is unclear" ([18], p. 428); note that the greek word firstly translated here by "invisible", i.e., adelos, also means "uncertain"). Similarly, in Aristotle's philosophy, to phainomenon usually represents "what appears according to the senses" as opposed to "what is", but another meaning of to phainomenon may be found in his works, which is "the objective fact", fully deducible from sensitive experience ([37], pp. 78-83), likely as opposed to constructions of the mind. This persisting ambiguity is still present nowadays as regards the perception of biological reality: is reality the hidden under the visible that can explain it, or is it on the contrary just what is apparent, all explanations of hidden causes being artificial and not to be taken for granted? In fact, still following Aristotle, appearance is always to be considered as appearance to someone [37]. Nowadays by changing levels of observation, what was considered as a hidden mechanism with respect to macroscopic observation may appear as completely phenomenological and need going deeper under the surface to understand it. One has to make a choice for the separation between levels of observation, one for what is considered as apparent, under which will lie the others, for what should be hidden explanations for observations performed at the apparent level. In the sequel, "mechanisms" will be understood as occurring at the molecular level (at which drugs are supposed to exert their effects), the levels above the molecular being considered as "phenomenological", in the sense that they are the usual observation levels (including sometimes the intracellular for cell physiology), but also that understanding and accurately representing what is observed there needs investigating underneath, i.e., at the molecular level. 


\subsection{At the subcellular level: Intracellular signalling pathways}

\subsubsection{Mathematical bases}

Intracellular signalling pathways, i.e., chains of biochemical reactions, that control the cell cycle and drug processing mechanisms are beginning to be well understood and their evolution can be described by differential equation models [8, 82, 83, 211].

Such deterministic equations rely on the law of mass action used in chemistry, that states that if a compound $Z$ is formed by the encounter (of stochastic nature: products of concentrations here come simply from probabilities of encounter of the molecules themselves, their presence at random locations in the cytoplasm being considered as independent events) of two compounds $X$ and $Y$ according to the reversible reaction

$$
X+Y \underset{k_{-1}}{\stackrel{k_{1}}{\rightleftharpoons}} Z
$$

then the resulting differential system writes:

$$
\begin{aligned}
& \frac{d[X]}{d t}=-k_{1}[X][Y]+k_{-1}[Z] \\
& \frac{d[Y]}{d t}=-k_{1}[X][Y]+k_{-1}[Z] \\
& \frac{d[Z]}{d t}=k_{1}[X][Y]-k_{-1}[Z]
\end{aligned}
$$

(account being not taken of further reactions involving the same compounds with other chemical species). Another type of reaction describing enzyme kinetics, and also based on the law of mass action (with the additional so-called quasi-equilibrium hypothesis for the intermediate complex of the reaction), is Michaelis-Menten kinetics, here written for the consumption of a substrate $[S]$ :

$S+E \underset{k_{-1}}{\stackrel{k_{1}}{\rightleftharpoons}} C \stackrel{k_{2}}{\rightarrow} E+P$, where $E, S$, and $P$ stand in this enzymatic reaction for substrate, enzyme, product of reaction, respectively, and $C$ is the intermediate complex $E \sim S$. The law of mass action writes:

$$
\begin{aligned}
\frac{d[S]}{d t} & =-k_{1}[E][S]+k_{-1}[C], \\
\frac{d[E]}{d t} & =-k_{1}[E][S]+k_{-1}[C]+k_{2}[C] \\
\frac{d[C]}{d t} & =k_{1}[E][S]-k_{-1}[C]-k_{2}[C] \\
\frac{d[P]}{d t} & =k_{2}[C]
\end{aligned}
$$

and by adding the "quasi-equilibrium" hypothesis, that states that $\frac{d[C]}{d t} \approx 0$ in the third equation (without $[C]$ being actually constant, i.e. one only replaces the left hand side of the third equation 
by 0 ), one obtains by straightforward computation a kinetic reaction of the (Michaelis-Menten) form:

$$
\frac{d[S]}{d t}=\frac{-V_{\max }[S]}{K_{m}+[S]}
$$

where $V_{\max }=k_{2}[E]_{0}$ and $K_{m}=\left(k_{-1}+k_{2}\right) / k_{1}$.

With more intermediate reactions and a few simplifying hypotheses, one can obtain a generalisation in the case of a cooperative enzyme (as shown, e.g., in [137], Chap. 1), the so-called Hill kinetics:

$$
\frac{d[S]}{d t}=\frac{-V_{\max }[S]^{n}}{K_{m}^{n}+[S]^{n}}
$$

where $n$ is some positive exponent, usually an integer, e.g., 5 or 10 , high values of $n$ being used to represent sharp state transitions between 0 and the maximum speed of reaction $V_{\max }$.

These two reaction types (law of mass action, and Michaelis-Menten or Hill kinetics), both non linear as are most mechanisms described in biology, are the basis for modelling molecular reactions in intracellular signalling pathways, that describe activation (including autoamplification) and inhibition mechanisms. Control of the cell cycle, but also drug processing, and the behaviour of various biological oscillators [112, 211], including circadian clocks [32, 229], that are known to impact on the cell division cycle [194] and on the activity of different drug processing enzymes [273], may be physiologically represented by such systems of ordinary differential equations (ODEs) $[165,166]$.

\subsubsection{Systems biology, or computational biology}

One can define this new discipline emerging in the large field of biology as the description of (most often intracellular) biological phenomena by large numbers of equations (or logical rules to describe temporal evolutions), resulting in systems that are usually out of reach of mathematical analysis, but can be used to perform quantitative predictions. Systems biology results from the confluence of mathematical biology, biochemistry, biophysics and bioenergetics, molecular biology and bioinformatics [269, 270]. Starting from questions about regulation of cell metabolism [125] (at a time when the term "systems biology" had not been coined), it has then developed in an autonomous field of knowledge to which biologists are sensitive, for in many aspects it yields "virtual cells", i.e. systems simulating the behaviour of cell systems, with little prerequisite mathematical knowledge [7, 142]. It is thus firstly directed at describing, rather than analysing, cell behaviours, and the cellular interaction systems under consideration are quite large, as may be seen in $[149,150,151]$. The problem of parameter estimation by statistical methods applied to observed data in such big systems has yielded new methods, based on Bayesian and Monte Carlo techniques [87, 126]. But also, recent works by mathematicians, aiming at model reduction [225] raise reasonable hopes that simplifying these cellular systems with the purpose of answering limited questions (that can be related to the use of specific drugs, for instance) will bring back systems biology into the field of mathematical analysis. 


\subsection{The cell division cycle and its control seen at the single cell level}

\subsubsection{Modelling the cell cycle}

Molecular reactions described by ODEs are also used to represent evolution in the cell division cycle until mitosis, using variables that are concentrations in cell cycle determinants such as cyclins and cyclin-dependent kinases (Cdks), but also other molecules: proteins E2F, pRb, p21, p27, p53, etc. One of the simplest models of the cell cycle is the so-called "mitotic oscillator", designed by A. Goldbeter, that describes in a minimal way the $G_{2} / M$ phase transition [110], with only 3 concentration variables: Cyclin B $(C)$, the $C y \operatorname{clin} B-C d k 1$ complex ( $M$, for "Mitosis Promoting Factor", MPF), and a protease $(X)$ for the degradation of $C y c l i n B$ :

$$
\begin{aligned}
\frac{d C}{d t} & =v_{i}-k_{d} C-v_{d} X \frac{C}{K_{d}+C} \\
\frac{d M}{d t} & =V_{M 1} \frac{C}{K_{C}+C} \cdot \frac{(1-M)}{K_{1}+(1-M)}-V_{2} \frac{M}{K_{2}+M} \\
\frac{d X}{d t} & =V_{3} M \frac{(1-X)}{K_{3}+(1-X)}-V_{4} \frac{X}{K_{4}+X} .
\end{aligned}
$$

With proper parameter values, it exhibits periodic solutions, that represent the regular sequence of divisions of a single cell. This model, as other cell cycle models, exhibits -with adequately chosen values of its parameters, in particular low values for the $K_{i}, 1 \leq i \leq 4$,- stiff dynamics for the $C y \operatorname{clin} B-C d k 1$ complex, thanks to a "zero-order ultrasensitive switch", a feature originally designed by A. Goldbeter [109] to represent fast kinase activation followed by inhibition, a bistable mechanism that is simply explained in [4] and has been recently revisited in [275].

Many more such cell cycle models have been designed, more complete, in particular by Aguda, and also Tyson and Novak [4, 209, 210, 260] and followers [49, 61], some of them with control by the circadian clock $[43,278]$, and it is not possible to cite them all. Their common aim is to elicit the physiological mechanisms of progression in the cell division process for a single cell, with known physiological controls, and they have allowed deep insight into understanding of the cell division cycle, the basic phenomenon for all proliferating tissue growth. They represent single-cell dynamics and have not been designed to describe dynamics of populations of cells.

\subsubsection{Modelling circadian clocks}

Various ODE models of circadian clocks have been proposed since the first one proposed by Goodwin $[115,116,236]$, one of the most robust and based on a physiological mechanism being the one by Leloup and Goldebeter [111, 165, 166], but others have been proposed, in particular by Forger [92, 93, 94], and by Tyson and Novak [259], reviewed in [95]. One of the most referenced 
ones, by Leloup and Goldbeter, writes:

$$
\begin{aligned}
\frac{d R N A_{m}}{d t} & =V_{s} \frac{K^{n}}{K^{n}+Z^{n}}-V_{m} \frac{R N A_{m}}{K_{m}+R N A_{m}} \\
\frac{d F R Q}{d t} & =k_{s} R N A_{m}-V_{d} \frac{F R Q}{K_{d}+F R Q}-k_{1} F R Q+k_{2} Z, \\
\frac{d Z}{d t} & =k_{1} F R Q-k_{2} Z .
\end{aligned}
$$

Designed to represent oscillations of the protein FRQ in Neurospora Crassa, it applies also, with 2 added equations, that represent intermediate phosphorylations between protein $F R Q$ and the transcription inhibition factor $Z$, to oscillations of the $P E R$ protein in Drosophila Melanogaster. The first equation represents transcription, i.e., synthesis of messenger RNA from gene expression in DNA at the nucleus level, the second stands for translation, i.e., synthesis in the cytoplasm of the protein $P E R$ itself (one of the first to have been identified as circadian in animals), and the last one describes the production, still in the cytoplasm, of the transcription inhibition factor $Z$ from $P E R$. Factor $Z$ will then be transported to the nucleus to exert a negative feedback on transcription, with high reactivity due to the Hill exponent $n$, usually set to 4 . This very simple model (transcription / translation / inhibition of transcription) is one of the most efficient to produce oscillations based on physiological principles. The Goodwin model $[115,116]$ is even simpler, with only one nonlinearity located at the transcription inhibition stage, but with a higher Hill coefficient $(n=9)$, and the representation of RNA degradation by a linear term (versus Michaelis-Menten in the LeloupGoldebeter model). Nevertheless, it proves useful when studying the behaviour of the clock under the influence of external inputs, such as temperature compensation [235] or (with an extension to include polyphosphorylations, as in the Leloup-Goldbeter model of $P E R$ oscillations) of genetic mutations [262].

\subsubsection{Circadian clocks and cell cycle interactions at the single cell level}

As mentioned earlier, models of the control of the cell cycle by circadian inputs exist $[43,278]$. They are based on the the fact that kinase kinase Wee1 (parameter $V_{2}$ in Goldebeter's minimal mitotic oscillator shown above), that phosphorylates kinase Cdk1 at the $G_{2} / M$ transition level, is expressed athe transcriptional level as a clock controlled gene. Does the converse influence, from cell cycle determinants toward the circadian clock, exist? At least this hypothesis, starting from the remark that transcription is uniformly inhibited during mitosis, has been studied in a recently published model, that uses the simple 3-variable Goldbeter model, with some added noise [135].

\subsection{Proliferation dynamics and its control at the cell population level}

The population of proliferating cells in a homogeneous tissue is the natural modelling level to represent healthy tissue and tumour growth and its control by drugs, since drugs act on individual cells, and growth is observed in cell populations. As far as one is interested in tissue growth control, more precisely in its pharmacological control, cell population dynamics models must include physiological control targets on cell cycle determinants: progression speed inside phases as 
measured by variations of cyclin concentrations, growth factor receptor occupancy and resulting intracellular signalling, cell cycle phase transitions and death rates.

\subsubsection{Physiologically structured partial differential equations (PDEs)}

Individual cells in proliferating tissues possess physiological structure features, as e.g., size, age in a phase of the cell division cycle if they are committed in it, maturity or differentiation status, genetic traits, and these features may be important to describe the cell population, its evolution, and its sensitivity to external controls. This is particularly true for models structured in age in the phases of the cell division cycle, for there exist drugs in clinical oncology that are specific of one phase, e.g., 5-fluorouracil of $S$ phase, vinca alkaloids of $M$ phase. Similarly, a genetic trait may represent the expression of some adaptability of the subpopulation that possesses it, e.g., the ability to resist the effects of a cytotoxic drug by enhancing intracellular mechanisms to degrade or expel it.

For these reasons, ODE models of cell population dynamics are less adapted than physiologically structured PDE models to accurately represent the evolution, free-running or submitted to an external molecular pressure, of a biological tissue, healthy or diseased, exactly in the same way as representing cell migration in a geometrically structured space will require space-structured PDEs (see below).

Physiologically structured PDE models (mostly age-structured models) are numerous and have a 80-year history since McKendrick's first model [14, 15, 16, 54, 120, 163, 181, 199, 197, 234]. They may be analysed (in their initial form, i.e., without transformation into delay deifferentiation equations) either by continuous semigroup theory $[14,15,16]$, or by asymptotic methods relying on the Krein-Rutman theorem [62, 202] and entropy principles described in [200, 217]. In their simplest form, they rely only on transport equations:

$$
\begin{aligned}
& \frac{\partial}{\partial t} n(t, a)+\frac{\partial}{\partial a}[v(a) n(t, a)]+[d(t, a)+K(t, a)] n(t, a)=0, \\
& v(0) n(t, a=0)=2 \int_{\alpha \geq 0} K(t, \alpha) n(t, \alpha) d \alpha .
\end{aligned}
$$

In this so-called renewal equation, $n(t, a)$ is a number, or density, of cells at time $t$ of age $a, d$ is a death rate, $K$ a renewal kernel standing for mitosis, and $v$ stands for a progression speed, i.e., speed of physiological age $a$ with respect to time $t$. Age $a$ is a lumped variable that may be considered as an aggregate of all determinants of progression in [a phase of] the cell division cycle (cyclins, proteic synthesis). This can be extended, as in [54] to model phases $(1 \leq i \leq I)$ of the cell cycle:

$$
\begin{aligned}
& \frac{\partial}{\partial t} n_{i}(t, a)+\frac{\partial}{\partial a}\left(v_{i}(a) n_{i}(t, a)\right)+\left(d_{i}+K_{i \rightarrow i+1}(t, a)\right) n_{i}(t, a)=0, \\
& \left.v_{i}(0) n_{i}(t, a=0)=\int_{\alpha \geq 0} K_{i-1 \rightarrow i}(t, \alpha) n_{i-1} t, \alpha\right) d \alpha, \quad 2 \leq i \leq I, \\
& n_{1}(t, a=0)=2 \int_{\alpha \geq 0} K_{I \rightarrow 1}(t, \alpha) n_{I}(t, \alpha) d \alpha,
\end{aligned}
$$


where $\sum_{i=1}^{I} \int_{\alpha \geq 0} n_{i}(t, \alpha) d \alpha=1$.

Being linear, these proliferation models exhibit an asymptotic behaviour that is strictly exponential, making them adapted to describe only the first stages of tumour growth, when no environmental negative feedback due to growth limitations by lack of nutrients or by mechanical constraints is present. This limitation induces to add non linear mechanisms accounting for such feedback, with exchanges of cells in both directions, from a surrounding non proliferating, or quiescent, population (described in next section). But as they are, these models already include targets for external control by drugs: death rates $d_{i}$, transition kernels $K_{i-1 \rightarrow i}$, that potentially contain $G_{1} / S$ and $G_{2} / M$ checkpoints with their control by protein $\mathrm{p} 53$, speeds $v_{i}$ that can describe growth factor influences (possibly annihilated by growth factor receptor antagonising), and are thus adapted to include further pharmacological inputs. In particular cell cycle phase specificities of different anticancer drugs acting in combination can be taken into account in such models. The asymptotic behaviour of these models is governed by their first eigenvalue $\lambda$ (the same for all phases; in some sense, using the Krein-Rutman theorem [217], $\left.n_{i}(t, a)\right) \sim e^{\lambda t} N_{i}(t, a)$, where $N_{i}$ is bounded), which can be related to a Malthus exponent measuring experimentally observed growth of the population. One may consider this first eigenvalue $\lambda$ as a quantification of proliferation and take it, in a therapeutic optimisation perspective, as an objective function to be controlled.

\subsubsection{Proliferation-quiescence PDE models}

Proliferation-quiescence models, classical [119, 120, 182, 183], or more recent [22, 23, 73], all rely on the idea that in proliferating tissues, not all cells proliferate, so that one can divide the population into two subpopulations, without any unrelevant space allocation (cells are all mixed up, as can be seen for example under the microscope in a bone marrow cell population sample), but according to their actual (or not) proliferating status. The main underlying biological hypothesis is that when environmental conditions are not adequate, proliferating cells become quiescent; and conversely, when proliferation is wanted, quiescent cells may be reintroduced in the proliferative compartment. This is indeed observed both in normal proliferating tissues (e.g., complete liver regeneration -without hyperplasia- induced by partial experimental hepatectomy in young rats [17]) and in tumours (where not all cancer cells proliferate, but quiescent cancer cells are a reservoir of dormant cells that can be recruited, for instance if the proliferating subpopulation has been badly hurt by a cytotoxic drug [36]). With simplifying hypotheses (death terms $\gamma$ and $\delta$ being independent of age $x$, reintroduction function $\beta$ from quiescence to proliferation and renewal kernel $K$ independent of time $t$ ), one can write such a standard model (inspired from MC Mackey's models) as: 


$$
\begin{aligned}
& \frac{\partial}{\partial t} p(t, x)+\frac{\partial}{\partial x} p(t, x)+[K(x)+\gamma(t)] p(t, x)=0, \\
& \frac{\partial}{\partial t} q(t, x)+\frac{\partial}{\partial x} q(t, x)+[\beta(t)+\delta(t)] q(t, x)=0, \\
& p(t, 0)=\beta(t) \int_{0}^{\infty} q(t, \xi) d \xi, \quad p(0, x)=p^{0}(x), \\
& q(t, 0)=2 \int_{0}^{\infty} K(\xi) p(t, \xi) d \xi, \quad q(0, x)=q^{0}(x)
\end{aligned}
$$

where $p^{0}$ and $q^{0}$ are initial conditions. As will be shown below, one can derive a delay differential equation $[182,183]$, with no age structure, from such a PDE model $[90,91]$.

These models include targets comparable to the ones displayed by linear models, but they also include possible control on the reintroduction function $\beta$, another way to represent growth factor control.

Such models, that represent exchanges between quiescent and proliferating subpopulations, can be branched to linear age-structured transport models (possibly describing the cell division cycle as subdivided in phases as described in the previous section), making them nonlinear. They should represent known exchanges, from a biological point of view, between $G_{0}$ (quiescence) and $G_{1}$ phases, and only the parameters of the exchange functions should be different from tumour to healthy tissue, as sketched in [22, 23]. Making use of exactly the same models (same targets or drugs), but with different parameters, it is possible to obtain for the cell populations asymptotic behaviours of qualitatively very different types, with convergence to a stable equilibrium in healthy tissues, and in tumours growth of the population according to exponential, polynomial or linear laws $[22,23,73]$.

\subsubsection{Models involving stem cell dynamics; maturity-structured models}

Stem cells dynamics may be represented by the generic model presented in the previous section, with a very imited proliferative subpopulation number, since at least in the haematopoietic bone marrow, it has been estimated that very few stem are actively committed in proliferation [71]. More generally, stem cells have been studied by probabilistic modelling [68, 70, 72], by cellular automata [233], by ODEs [192], by difference equations [139] and by PDEs [140] or delay differential equations $[183,186]$, with applications mainly in haematology and haematological diseases (in particular chronic myelogenous leukemia and cyclical neutropenia), where observations of the resulting mature cells populations are easy to perform in the clinic. The interested reader is invited to refer to the rich literature mentioned in the references.

In a PDE setting, adding one structure variable for maturity makes age-structured models able to account for several differentiation statuses among cells that are also proliferating, usually with exchanges between a proliferative and a quiescent compartment. This is especially adequate for fast renewing tissues, such as intestinal mucosa, and most of all the haematopoietic bone marrow. 
Transport equations are then of the following type [1]:

$$
\begin{aligned}
& \frac{\partial}{\partial t} p(t, x, m)+\frac{\partial}{\partial x} p(t, x, m)+\frac{\partial}{\partial m}(V(m) p(t, x, m))+\gamma(m) p(t, x, m)=0 \\
& \frac{\partial}{\partial t} q(t, x, m)+\frac{\partial}{\partial x} q(t, x, m)+\frac{\partial}{\partial m}(V(m) q(t, x, m))+[\beta(m, Q(t, m))+\delta(m)] q(t, x, m)=0
\end{aligned}
$$

where $Q(t, m)=\int_{0}^{\infty} q(t, m, \xi) d \xi$ and $\beta$ is a reintroduction function from quiescence to proliferation, positive and decreasing in age $x$, such that $p(t, m, 0)=\beta(m, Q(t, m)) Q(t, m)$.

Other models structured in age and maturity have been proposed $[1,184,185]$, with comparable transport equations. It is also possible to discretise the maturity variable to yield a proliferationquiescence model with communicating compartments for differentiation, with distinction between self-renewal and differentiation rates, as in [3]. This allows in principle easier identification from biological observation and tackling the problem of differentiation blockade that is always observed in Acute Myelogenous Leukaemia (AML), where in a particular case (Acute Promyelocytic Leukaemia) specific redifferentiation therapies exist [121].

\subsubsection{Delay differential equations for haematopoiesis}

Starting from age-structured proliferation-quiescence PDE models, and with additional assumptions, in particular on the transition kernel $K$ representing mitosis at the end of the proliferating phase, reduced to a Dirac measure, and on the reintroduction function $\beta$, supposed to depend only on $Q(t)=\int_{0}^{\infty} q(t, \xi) d \xi$, total population of quiescent cells (physiologically in a decreasing way to represent negative feedback), e.g. as $\beta(Q)=\frac{k \theta^{n}}{\theta^{n}+Q^{n}}, n \in \mathbb{N}^{*}$, one can integrate along characteristic lines (demonstrations in appendices in $[90,91]$ ) to obtain delay differential equations. More precisely, if $P(t)=\int_{0}^{+\infty} p(t, \xi) d \xi$, a simple system of delay differential equations [182, 183]:

$$
\begin{aligned}
& \frac{d P(t)}{d t}+\gamma P(t)-\beta(Q(t)) Q(t)+\beta(Q(t-\tau)) e^{-\gamma \tau} Q(t-\tau)=0, \\
& \frac{d Q(t)}{d t}+[\beta(Q(t))+\delta] Q(t)-2 \beta(Q(t-\tau)) e^{-\gamma \tau} Q(t-\tau)=0
\end{aligned}
$$

where $\tau$ is the duration of the proliferating phase, i.e., the cell cycle time and $K(\xi) d \xi=\delta_{\tau}(\xi)$. The initial condition on $Q$ on $[0, \tau]$ is given, again by integration along characteristics, by the solution to the ODE:

$$
\frac{d Q(t)}{d t}+[\beta(Q(t))+\delta] Q(t)=2 e^{-\gamma \tau} p^{0}(\tau-t)
$$

for $0<t<\tau$, where $p^{0}(x)=p(0, x)$ in the standard age-structured proliferation-quiescence PDE model above. 
This expression of the dynamics of a proliferating cell population by a delay system has been popularised in works on haematopoiesis, physiological or disrupted (e.g., in leukaemia), by MC Mackey and his followers in the last 30 years, with a recent aftermath of interest from the scientific community[2, 28, 57, 89, 90, 91, 124, 182, 183]. These models are also a possible framework for PK-PD modelling and drug delivery optimisation [89, 91], especially in haematology.

\subsection{Tissue organisation: Intercellular communications and outer controls}

\subsubsection{Synchrony in cycling cells}

Age-structured PDE models of the cell division cycle, as the ones presented above and in [55, 54], allow to theoretically follow the progression of cells in the cell division cycle, at a time when the experimental followup of individual cells or living cell populations (i.e., without destruction of the investigated cells, contrarily to previous classical imaging techniques, such as BrdU or Ki67 labelling [162]) begin to be accessible by recent cell fluorescence visualising techniques with sharp contrast, in specified parts of the cell cycle: $G_{1}$ on the one hand, $S-G_{2}-M$ on the other hand [237, 238]. Techniques to simultaneously identify other transitions are being actively searched-for and will likely be available in short time. Other non-cell-destructive techniques based on luminescence, hybridizing genes with luciferase in cultured cells or by producing transgenic mice [276], rather than fluorescence could be relevant in principle in the same context but do not seem to have been used for the investigation of cell cycle determinants so far.

On another side, the use of a cellular automaton model [9] including variability on the phase transition function between $G_{2}$ and $M$, stiff or with overlapping between phases, to represent synchrony between cells with respect to cell cycle phase timing, has shown that the response of cell populations to chronotherapeutic schemes for anticancer drugs may be radically different according to this synchronisation status.

In a continuous PDE setting, linear equations endowed with an advection term representing transport of cell populations according to physiological variables (age or cyclin concentration) with a speed of progression in a cell cycle phase may account for such softness or stiffness in phase transitions. This question has been a matter of research for quite a long time already, both from the mathematical and from the experimental point of view, see [21, 48, 261]. An example of such an equation, structured in age $a$ and cyclin $x$, designed to represent the passage through he restriction point of $G_{1}$ phase $[33,63,279]$ by a "leak" function $L$ (leaking of cells in $G_{1}$ to quiescent phase $G_{0}$ ) and the evolution in $G_{1}$ phase according to a variable speed $\Gamma_{1}$, is:

$$
\frac{\partial}{\partial t} p(t, a, x)+\frac{\partial}{\partial a}\left(\Gamma_{0} p(t, a, x)\right)+\frac{\partial}{\partial x}\left(\Gamma_{1}(a, x) p(t, a, x)\right)+\left(L(a, x)+d_{1}\right) p(t, a, x)=\ldots
$$

where ... stand here for source and loss terms, that can be related to exchanges with previous and subsequent phases. In this transport equation [22, 23], the parameter $\Gamma_{0}$ denotes the evolution speed of physiological age $a$ with respect to time $t$, which is assumed to be constant in this model; if for example $\Gamma_{0}=0.5$, it means that physiological age $a$ evolves twice as slowly as real time $t$. Similarly, the function $\Gamma_{1}$ represents the evolution speed of $C y c l i n ~ D /(C d k 4$ or 6$)$ with respect to time in $G_{1}$ phase, i.e., $\Gamma_{0}$ times the speed $d x / d a$ of $x$ with respect to physiological age $a$ (the 
coupling between the two structure variables being modelled by another equation, that describes Cyclin $D / p 27$ kinetics). The function $\Gamma_{1}$ in the advection term may be chosen to represent, in a more or less stiff way, the transition to the next phase: the stiffer is its passage from low to high values (or the opposite), the more synchronised is the population of cells represented here by its density $p(t, a, x)$.

\subsubsection{Differences in tissue organisation between healthy and tumour cells}

A working hypothesis, supported by biological observations at the protein or mRNA level, is that healthy cells are entrained by circadian rhythms and well synchronised with respect to the cell division cycle [32, 246], but that tumour cells are less synchronised [118], less obeying synchronising inputs (from the clock, from humoral messages such as cortisol), which could give them a proliferation advantage. This hypothesis remains to be documented. Preliminary studies on linear models of the McKendrick type for the cell cycle, with imposed periodic control on transitions $[52,55]$, supposed to represent a circadian control rhythm, have shown that it is not possible in general to decide in favour of a proliferation advantage to periodic control versus no control (or the opposite) of the phase transitions without adding mathematical hypotheses. A complementary point of view, using a delay differential model for cell proliferation, is presented in [27]. Such additional hypotheses on mechanisms are still expected to be guided from observations to make realistic models.

Much remains to be done to study cell synchronisation with respect to cell cycle phases by using such models. The choice of speed functions (such as $\Gamma_{1}$ ) representing the evolution of concentrations of Cyclins and Cyclin-Cdk complexes is a way to introduce preexisting biological knowledge at the individual cell level. The fact that, as mentioned above [237, 238], at least the $G_{1} / S$ transition is now reachable in individual living and evolving cells or cell populations by rather simple fluorescence techniques as a sharp contrast of colours (red/green) should stimulate model design and their parameter identification in healthy and in tumour tissue.

\subsubsection{Ways by which cells may be coupled and synchronised}

Synchronisation of cells with respect to cell cycle phases is obtained in experimental conditions either by sorting cells according to their physical properties, e.g., by fluorescence (FACS = fluorescence activated cell sorting), or by temporary chemical blockade of the cell division cycle, e.g., by deprivation in growth factors. But when and how is it obtained physiologically? The molecular mechanisms seem to be little known. Whereas in excitable cells electric coupling by transmembrane action potential diffusion, and in some other particular cases, delta-notch or juxtacrine signalling, or sharing molecules between cells through gap junctions may be considered, in general, in peripheral tissues, cells do not exchange information through intercellular communication. So that another possibility to explain cell synchronisation in tissues is that they obey common orders received by messages sent from a common centre, and as has already been mentioned about perturbed control mechanisms of cell cycle progression, the central pacemaker of the circadian system, the so-called suprachiasmatic nuclei (SCN), constituted of about 20000 neurons in mammals, is a good candidate to be a chief synchroniser for local circadian clocks (that are found in every 
single nucleated cell of the body). Neurons communicate very fast, so that a common period of osccillations is quickly established at the central level, and transmitted to the periphery by neural and hormonal messengers [214]. Then, through the known coupling between the clock and some particular determinants of cell cycle controls that are Cyclin-Cdk complexes that govern $G_{1} / S$ and $G_{2} / M$ transitions by gating, this central conductor may synchronise in their turn cells in the cell cycle, so that the circadian system is a good candidate to ensure this cell synchronisation. This can be modelled, as in [51], by networks of oscillators.

\subsection{Macroscopic models of tumour growth}

Less adequate for the inclusion of pharmacological control targets, but simpler to handle, many continuous or stochastic models have been proposed to describe solid tumour growth from a macroscopic point of view. They have in common to be most often used for prediction of phenomenological growth behaviour at the visible level, with little focus on molecular mechanisms, but often good comparison of their outputs with images of tumours. They represent more a physicist's than a physician's point of view, i.e., their purpose is oriented toward macroscopic description and interpretation of radiologic or RMI images, aiming at tumour spontaneous evolution prediction, rather than toward therapeutics.

\subsubsection{Simple growth models with ordinary differential equations (ODEs)}

The simplest model, firstly designed to describe tumour growth, is the exponential model, or linear model, if one refers to the ODE rather than to its solution. Assuming that there is no limitation to growth, each cell dividing at a constant rate $\lambda$, i.e., with constant doubling time of the cell population given by the relation $T_{d}=\ln 2 / \lambda$, the model describing cell population (number) evolution with unlimited growth is simply

$$
\frac{d x}{d t}=\lambda x
$$

Naturally such a simple model can only describe very early stages of tumour growth, when no limitation by nutrient supply or mechanical constraint is present. To take account of these natural limitations, and others, the continuous logistic model has firstly been proposed (by Verhulst in 1838 , in another context). It writes

$$
\frac{d x}{d t}=k x\left(1-\frac{x}{x_{\infty}}\right), k>0,0<x(0)<x_{\infty}
$$

and has two equilibrium points: $x=0$, unstable, and $x=x_{\infty}$, stable, i.e., the solutions, initially exploding exponentially at a rate $k$, will eventually converge to the equilibrium value $x=x_{\infty}$.

Another model, still popular among radiologists observing tumour growth images, is the socalled Gompertz model:

$$
\frac{d x}{d t}=k x \ln \frac{x_{\infty}}{x}, x(0)>0
$$


which is nothing but the linear model in the variable $y=\ln \left(x_{\infty} / x\right)$. As in the logistic model, its solutions are S-shaped curves, with initial exponential growth and eventual convergence toward the equilibrium value $x=x_{\infty}$. One of its drawbacks is that $x(0)$ must be strictly positive, i.e., it cannot give access to low initial growth values.

All these simple models [206] are clearly analytically integrable and are usually too coarse to account for observations of real tumour growth curves, but can be compared with data on tumour growth curves as a reference scale. Another model of the same type [190, 245] has tried to give account of what is often observed with tumours growing in laboratory mice: initial exponential growth followed by linear growth, i.e., its eventual solutions are lines with constant slope $p$. This "ad hoc" model writes:

$$
\frac{d x}{d t}=\frac{k x}{\left(1+\left(\frac{k}{p} x\right)^{\psi}\right)^{1 / \psi}}
$$

with a high value of $\psi$, e.g., $\psi=20$, which yields the expected behaviour in a smooth manner. The same idea could be followed to combine Gompertz growth followed by linear behaviour, another feature observed at times with tumour growth curves in mice, possibly attributable to an "angiogenic switch" transition, when the tumour succeeds in diverting an important part of the blood flow to its own benefit:

$$
\frac{d x}{d t}=p\left(1+\left(\frac{k}{p} x \ln \frac{x_{\infty}}{x}\right)^{\psi}\right)^{-1 / \psi} .
$$

Coarse and ad hoc as they are, these models have the advantage to involve few parameters, and the modification of these parameters when different cytotoxic drugs are delivered to laboratory animals has been proposed by their authors to be used as a tool to compare their therapeutic efficacy. But they cannot be used to describe the mechanistic (molecular) effects of drugs on their cellular targets and combinations of these drugs acting on different targets in a complementary and optimised way.

\subsubsection{Simple proliferation-quiescence ODE models}

Simple models, still without any physiological (nor spatial) structure, but with the laudable concern to represent exchanges between subpopulations of cells in proliferation on the one hand and in quiescence (i.e., not committed in the cell division cycle, otherwise said in $G_{0}$ phase) on the other hand, have been proposed $[119,153]$. They rely on the observation that according to local environmental conditions (in oxygen, glucose, growth factors), cells can pass from proliferating to non proliferating state, and vice-versa, without any topographical preference. The avowed aim of such modelling was to give an explanation supporting Gompertz-like growth behaviour for tumours.

In its simplest form, the model writes

$$
\begin{aligned}
\frac{d P}{d t} & =\left(\beta_{P}-\mu_{P}-r_{0}(N)\right) P+r_{i}(N) Q \\
\frac{d Q}{d t} & =r_{0}(N) P-\left(r_{i}(N)+\mu_{Q}\right) Q
\end{aligned}
$$


where $\beta$ is a birth term, and $\mu_{P}$ and $\mu_{Q}$ are death terms in the two subpopulations, proliferating $(P)$ and quiescent $(Q)$, and the functions describing recruitment in proliferation $\left(r_{i}\right)$ and leak to quiescence $\left(r_{0}\right)$ may take the form of Hill functions $r_{i}(N)=\frac{\beta L^{\delta}}{L^{\delta}+N^{\delta}}$ and $r_{0}(N)=\frac{\alpha N^{\gamma}}{K^{\gamma}+N^{\gamma}}$, where $N=P+Q$.

It may be tuned so as to yield monotonic convergence toward a stationary equilibrium, as in the logistic and Gompertz models.

\subsubsection{Individual-based models}

To describe on a physical basis (in particular focusing on biomechanical phenomena) cell by cell interactions between cells, and between cells and their environment, that lead to observable tumour growth, individual-based (or agent-based) models have been proposed, relying on rules, comparable to others developed for cellular automata, that define, on a stochastic basis but within a frame constrained by precise physical principles, when a cell will divide and what will be its fate in the constituting population. One can find in $[74,100]$, and in a comparative study between the outputs of these models and of PDEs [42] for solid tumours, and in [30] for proliferating clones in the bone marrow, examples of these models. They rely on much computational effort and provide macroscopic moving images of tumour growth that can be compared with data. A time may come when these models will be used to represent the action of drugs on tumours, but for the present time molecular aspects, especially of the action of drugs on the cell cycle, are lacking. Other pitfalls of these models is that they often demand large computational times (so that hybrid models have also been proposed, combining them with PDEs) and that their mathematical analysis seems out of reach, contrarily to the case of PDE models.

\subsubsection{Reaction-diffusion systems}

These models, mathematically studied in the book by N. Britton [39] (with a point of view that is more interested in applications to modelling in ecology than in tumour dynamics), are all spatially structured PDE models, since the diffusion term, a second order derivative, describes the distribution in space of a particle, a molecule or a cell. They constitute a very rich domain of the modelling of tumour growth and invasion, of which I only give here a brief report. These models are seldom concerned with cancer therapeutics by drugs (with at least the exception of [133]).

One of the first of reaction-diffusion systems, which may be taken as a paradigm of their behaviour, is the KPP-Fisher equation, presented in the book by J. Murray [206]. A spatially structured PDE, it describes Fickian diffusion for a chemical species, particle or cell of density $u$ interacting with its environment:

$$
\frac{\partial u}{\partial t}=\nabla \cdot(D \nabla u)+f(u)
$$

where the diffusion matrix $D$ may depend on space, the derivative $\nabla$ is the spatial derivative, and in one dimension $f(u)=\rho u(1-u)$ is the reaction term, representing interaction of a particle (diffusing cell or molecule) with its environment. It has the property to yield "travelling waves", 
i.e., shifting in space at constant speed of a front of particles, a feature that is actually observed, and has been successfully used to describe tumour invasion in different contexts, in particular in the brain [254, 255], but also leukaemic proliferation in the bone marrow [29, 77].

Other models have been elaborated to describe general competition between healthy and tumour cell populations, e.g. [243], or more specific phenomena, such as the Gatenby-Gawlinski model [101, 102] that describes competition between a population of healthy cells $N_{1}$ (that do not diffuse) and a population of tumour cells $N_{2}$, in the presence of excess $\mathrm{H}^{+}$ions $(L)$ :

$$
\begin{aligned}
\frac{\partial N_{1}}{\partial t} & =r_{1} N_{1}\left(1-\frac{N_{1}}{K_{1}}-\alpha_{12} \frac{N_{2}}{K_{2}}\right)-d_{1} L N_{1} \\
\frac{\partial N_{2}}{\partial t} & =r_{2} N_{2}\left(1-\frac{N_{2}}{K_{2}}-\alpha_{21} \frac{N_{1}}{K_{1}}\right)+\nabla \cdot\left(D_{2}\left(1-\frac{N_{1}}{K_{1}}\right) \nabla N_{2}\right) \\
\frac{\partial L}{\partial t} & =r_{3} N_{2}-d_{3} L+D_{3} \nabla^{2} L
\end{aligned}
$$

or the Anderson-Chaplain model [11] (see also [12,106]) for local invasion by tumour cells $(n)$ that degrade the extracellular martrix $(f)$ by a metalloprotease $(m)$ in presence of its inhibitor $(u)$ :

$$
\begin{aligned}
\frac{\partial n}{\partial t} & =\overbrace{D_{n} \nabla^{2} n}^{\text {random motility }}-\overbrace{\chi \nabla \cdot(n \nabla f)}^{\text {haptotaxis }}, \\
\frac{\partial f}{\partial t} & =-\overbrace{\delta m f}^{\text {degradation }}, \\
\frac{\partial m}{\partial t} & =\overbrace{D_{m} \nabla^{2} m}^{\text {diffusion }}+\overbrace{\mu n}^{\text {production }}-\overbrace{\theta u m}^{\text {neutralisation }}-\overbrace{\lambda m}^{\text {decay }}, \\
\frac{\partial u}{\partial t} & =\overbrace{D_{u} \nabla^{2} u}^{\text {diffusion }}+\overbrace{F(m, f)}^{\text {production }}-\overbrace{\theta u m}^{\text {neutralisation }}-\overbrace{\text { हu }}^{\text {decay }} .
\end{aligned}
$$

Such a model is in principle adapted to study the inhibition of tumour invasion by metalloprotease inhibitors, a therapeutic way that has not encountered much success in the clinic, but may be revived, in particular in combination with other anticancerdrugs with different mechanisms, antiangiogenic (inhibiting tumour vascularisation), cytotoxic or cytostatic (inhibiting cell proliferation by killing cancer cells or slowing down their growth).

\section{Drug modelling for cancer therapeutics: Whole body dispo- sition and intracellular action}

Statistical (blackbox) representations of the action of drugs in populations of patients have been in use in clinical pharmacology for some time, using abstract compartment models with minimum concern about their mechanistic (i.e., physiological) relevance, their aim being to accurately predict evolution of drug concentrations in blood, and their efficacy in (large) populations of patientts. 
The therapeutic effect in the case of anticancer drugs, is more difficult to assess than for drugs with shorter term effects (e.g., acting on blood pressure, airflow, renal function, etc.) and may be measured only by long term outputs, such as by response to treatment measured by tumour image shrinking, and in a limited number of cases, on blood concentrations of biomarkers, the endpoint of all cancer treatment evaluation being survival time after months or years. How can one relate such a distant output as a survival duration to the blood concentration profile of a drug $\left(C_{\max }\right.$, peak blood concentration, and $A U C$, area under curve of blood concentration plotted against time, i.e., total delivered dose)? As expressed by M. Ratain and R. Mick, (p. 138 of [241]): "The major distinction [between anticancer drug pharmacology and the pharmacology of other drugs] is the marked time lag between the last measured plasma concentration and the first major therapeutic or toxic effect." Clearly, very different time scales are involved, and the core scene of anticancer drug action: the cell, is not represented in those classical pharmacological models, that, in dealing with cancer, naturally encounter more difficulties than in most other pathologies, where quantification of observations and results is easier.

\subsection{Pharmacokinetics-Pharmacodynamics (PK-PD)}

"Pharmacokinetics is the study of what the body does to the drug, and pharmacodynamics is the study of what the drug does to the body." This often reported pharmacological motto must be taken word for word, meaning that as long as the drug has not reached its target (therapeutic or toxic) i.e., "done something to the body", then one is dealing with pharmacokinetics, including at the interstitial tissue level and at the intracellular level, for drug concentrations, which implies that there is such thing as intracellular pharmacokinetics. Then comes intracellular pharmacodynamics, that should relate in a mechanistic way intracellular drug concentration profiles (and their timings) with the drug effects on its cell targets, at the individual cell level. Only after these stages can one assess anticancer drug effects at the tissue level, tumour or healthy, by its effects on a proliferation rate in a cell population.

In this extended domain of pharmacology, there exist two main different points of view: from the populational one, statistical (and static) studies are performed at the level of a population of patients, and aim at predicting treatment outcomes as a function of drug doses, account being taken of patient specificities, but are seldom concerned with physiological representations. On the contrary, from the mechanistic point of view, studies try to take maximum advantage of physiological knowledge about drug processing mechanisms, at various levels of description, using dynamic methods (differential equations) to describe the fate of drugs. The latter point of view is in particular the only one possible when dealing with chronotherapeutics, in which the time schedule of drug delivery is fundamental.

Convergence between these two points of view will hopefully come in the future, in particular from considerations on genetic polymorphism of drug processing enzymes in mechanistic models, but they constitute two different fields at the present time. A recent presentation of this evolving field is presented in the book [257]. 


\subsubsection{PK-PD: populational point of view}

What pharmacologists call pharmacokinetics is usually only blood pharmacokinetics, whereas pharmacodynamics in the case of anticancer drugs that treat solid tumours are assessed only at the whole body level. What interests pharmacologists and scientists dealing with populational PKPD is to describe by statistical means in populations of patients, using as inputs classical blood pharmacokinetic constants as peak concentration $C_{\max }$ or total delivered dose $A U C$, the dependence of chosen endpoints of therapeutic efficacy (response rate at defined times after treatment, survival rate) upon these inputs. Such dependence can be assessed conditionally in various factors of interindividual variability, such as age, gender, status with respect to genetic polymorphism in drug processing enzymes (when available), etc. When several drugs are in use, these statistical methods allow to recognise whether their effects are opposed, or additional, or synergistic (one drug cooperating with another to potentialise its effects, which may be represented by, e.g., a bilinear term added in linear expressions linking an endpoint statistical variable to input factors).

Closer to a mechanistic point of view, some of these methods encompass the concept of an effect compartment [219] into which drugs enter coming from the plasma, this entry being represented by a first-order linear differential equation. Then an equilibrium state is assumed, as is usually the case in the frame of classical (populational) PK-PD.

The dominant perspective in populational PK-PD studies presently seldom includes a mechanistic point of view. The aim of populational PK-PD is, as already mentioned, to make predictions in populations of patients in a global manner, that hardly encompasses mechanistic details on the fate of drugs in the organism. Nevertheless, though mechanistic models are underdeveloped by comparison with populational ones (as noted in [242]), a tendency of "the PK-PD field clearly moving towards mechanistic modelling" [60] has been observed and should continue.

\subsubsection{PK-PD: mechanistic point of view}

According to the mechanistic point of view, all that is known from physiology at the molecular level, which is the level at which drugs are administered, diffuse, exert their action, are metabolised and excreted, is of interest, and chemical reactions described by differential equations, with their kinetic constants, are the main tools of description.

This point of view is less broadly represented than the previous one, and mostly by individual attempts, relying for identification of the model parameters either on estimations from pharmacological literature, or from combinations of in-vitro and in-vivo experiments. Their aim is to describe all relevant mechanisms that can explain differences of behaviours with respect to drug response in different individuals: genetic variations in drug enzyme processing, presence or absence of active efflux drug transporters, variations in concentrations of drug targets, etc.

To give an example of the rapidly growing number of equations involved in such representations, here is what a rather simple tentative model of mechanistic intracellular PK may produce [67]. It is designed to describe at the cell level the transformation of the prodrug irinotecan (CPT11) into its active form SN38 by enzyme carboxylesterase (CES), and its subsequent degradation into inactive glucuronide SN38-G, through conjugation to a sugar radical by enzyme UGT1A1. Simultaneously, an active drug transporter, BCRP, here named ABCG2 [117], is supposed to expel 
from the cell both CPT11 and SN38 and to be induced in its activity by concentrations of CPT11 and SN38... many assumptions that require in-vitro pharmacological experiments, not all of them performed thus far. Furthermore, this is only part of the model, since the pharmacodynamic subsequent part (binding of SN38 to Topoisomerase I and DNA to form first a cleavable complex, then an irreversible complex, the reality of DNA damage by Irionotecan) is still the object of work in progress, not presented here. The extracted intracellular PK model writes:

$$
\begin{aligned}
\frac{d[C P T-11]}{d t}= & \operatorname{In}(t)-k_{1} \frac{[C E S][C P T-11]}{K_{m 1}+[C P T-11]}-k_{t 1} \frac{[A B C G 2][C P T-11]}{K_{t 1}+[C P T-11]}, \\
\frac{d[S N 38]}{d t}= & k_{1} \frac{[C E S][C P T-11]}{K_{m 1}+[C P T-11]}-k_{t 2} \frac{[A B C G 2][S N 38]}{K_{t 2}+[S N 38]}-k_{2} \frac{[U G T 1 A 1][S N 38]^{n}}{K_{m 2}^{n}+[S N 38]^{n}} \\
& -k_{c o m p l}[S N 38][T O P 1]\left[A D N_{l i b r e}\right]+k_{c o m p l}[C C], \\
\frac{d[S N 38-G]}{d t}= & k_{1} \frac{[U G T 1 A 1][S N 38]^{n}}{K_{m 1}^{n}+[S N 38]^{n}}-k_{d 1}[S N 38-G], \\
\frac{d[A B C G 2]}{d t}= & k_{t 2}[A B C G 2]\left(\frac{[S N 38]}{K_{t 2}+[S N 38]}+k_{t 1} \frac{[C P T-11]}{K_{t 1}+[C P T-11]}\right)-k_{d 2}[A B C G 2] .
\end{aligned}
$$

In this example of pharmacokinetic system, one finds the most common ingredients to design mechanistic models of biochemical reactions, earlier mentioned in the text ("Intracellular signalling pathways") as law of mass action, Michaelis-Menten and Hill kinetics.

One can from this example, and the large number of parameters to be identified to validate this model, take the measure of the long distance that still exists between mechanistic modelling at the cell level, and clinical applications. Nevertheless, the continuous development of intracellular investigation means (as for the cell cycle determinants by fluorescence techniques) leaves reasonable hopes of such parameter identification in a close at hand future.

\subsubsection{Whole body physiologically based PK-PD modelling}

This term and its acronym, "WBPBPKPD", advocated by Malcolm Rowland [257] should relate mechanistic (i.e., physiologically based) modelling at the drug effect level, which for anticancer drugs are cell target(s), as presented in the previous section, with an already more developed mechanistic modelling field, that is whole body physiologically based pharmacokinetics (WBPBPK). It represents the fate of an administered drug in the whole organism, according to ADMET guidelines (absorption, distribution, metabolism, excretion, toxicity), using compartments that are not abstract, but anatomical: gastrointestinal tract, blood, liver, non eliminating tissue, efficacy and toxicity compartments (tumour, bone marrow) according to the chosen drug. In this field, interesting modelling studies have already been published, either on a particular drug, e.g., capecitabine [258], or on the more general and theoretical issue of tissue distribution, uniting plasma and tissue pharmacokinetics, from blood to intracellular concentrations [147]. Lack of observations in cellular or intermediate hidden compartments often leads to lump variables in these models, as studied in [147] or already in [208], to make their identification possible. 
It is noteworthy that identifying such WBPBPKPD models for the present time represents lots of experimental work in vitro, in vivo and for rescaling from in vitro to in vivo in different animal species, and from them to Man, each sequence of experiments needing to be done separately for each drug under study, a process that is far from being automated.

\subsection{Chronotherapeutics: pharmacokinetics and pharmacodynamics}

Chronotherapeutics, that most often means circadian chronotherapeutics [167, 168, 170, 171, 205], takes advantage of the fact that drugs exert their effects in different ways according to the time of the day at which they are administered. This has been in use for the last 15 years or so in the clinic of cancer, by delivering cytotoxic drugs 5-fluorouracil and oxaliplatin according to variable infusion flow time schedules, in the treatment of colorectal cancer, and combination with surgery, yielding successful results, see e.g., [108] for a recent study. The explanation of the mechanisms by which chronotherapeutics works seem to involve both chronopharmacokinetic and chronopharmacodynamic components. For instance, oxaliplatin PK has been shown to have circadian rhythmicity $[35,169]$, and this may be related to circadian rhythms in circulating or cellular compounds, mainly reduced glutathione, binding this molecule [174, 175]. More generally, circadian rhythms in the activity of different drug processing enzymes, such as dihydropyrimidine dehydrogenase (DPD) for 5-fluorouracil [19], have been found, explaining circadian effects in terms of chronopharmacokinetics. But other circadian rhythms exist, that are expressed on cell cycle determinants of the cell division, the pharmacodynamic target of anticancer drugs, as previously mentioned [32, 194, 229], which makes chronotherapeutics also a matter of chronopharmacodynamics.

From these considerations, it results that mechanistic PK-PD models of chronotherapeutics should take into account circadian rhythmicity both at the level of drug metabolism (intracellular and extracellular, e.g, plasma and liver processing) and at the level of the cell division cycle control.

\subsection{Pharmacodynamics of anticancer drugs: acting with drugs on the cell cycle}

Anticancer drugs are diverse and have different cellular targets. Briefly, one must represent the action of alkylating agents, such as oxaliplatin, directly by DNA damaging, i.e., binding irreversibly to it by covalent bonds [46, 80]; of antimetabolites such as 5-fluorouracil [176] or irinotecan [220], by inhibition of their target activity (an enzyme), of cyclin dependent kinase inhibitors, such as roscovitin or indorubicins [227], by blocking the cell cycle at phase transitions, etc. The interest of describing in detail these cytotoxic mechanisms is that in a model of the cell cycle, their synergistic action (known in the clinic) can be taken into account and subsequently optimised by delivering multidrug infusion according a theoretically optimised time schedule, timing being understood here as cell cycle timing. Note that since a circadian control exists, with entrainment of the cell cycle period $T_{d}$ (at least when the circadian system is conserved), by eliciting the relationship between circadian clocks and cell cycle timing, one has a natural circadian rationale to deliver 
cytotoxic drug with complementary effects according to an optimised cell cycle time, provided that one also takes into account the circadian rhythms of drug cell processing.

These are still only principles for designing optimised drug delivery time schedules, with no applications so far. Applications will need in vitro studies on cell cultures and in vivo experimentations in laboratory rodents, on a basis that will be no more empirical, but guided by molecular modelling.

\subsection{Adjuvant pharmacodynamics: acting on the microenvironment and at the whole organism level}

Complementary treatments, some of which are already present in the clinic, such as antiangiogenesis drugs (fighting nurturing tumours), and others have not proved very efficient so far, as matrix metalloprotease inhibitors (fighting invasion of surrounding tissues by tumour cells that destroy the extracellular matrix by matrix degrading enzymes), may be represented in locoregional models, as is the Anderson-Chaplain model of cancer invasion presented earlier, see [230].

Beyond this locoregional level, i.e., beyond an immediate neighbourhood of a solid tumour, other adjuvant therapies may be represented in whole body pharmacodynamics by taking into account controls exerted at the whole organism level: by the circadian system [51] and its central pacemaker (assuming it to be a cell synchroniser, resynchronisation therapies by cortisol or melatonin have been proposed); by hormonal treatments (cortisol is often used in cancer treatment. . but has the drawback to depress the immune system) represented by their action on cell cycle phase transitions; by already mentioned immunostimulating treatments [280, 281, 282], provided that one uses a model of intervention of the immune system (such models are already available, see e.g., [272]).

\section{Anticancer pharmacological treatment optimisation}

Given a) a system of equations describing controlled cell proliferation at the cell population level, with a number of cells or a growth rate as output (whence an objective function may be defined); b) another one (PK-PD) for the proliferation control action exerted by drugs in an intracellular medium (containing drug targets, either of therapeutic efficacy or of unwanted toxicity) that one may consider as homogeneous in the absence of tissue topological data to take diffusion into account -but spatial PDE models for diffusion through membranes may also be considered when relevant information is available-; and c) a "whole body" system describing the fate of drugs from infusion to their cell target, it is then possible to set an optimal control problem of drug delivery, by defining constraints representing clinical limitations to the use of these drugs.

The control of the system will always be exerted by drugs, in the chosen context, but the forms of their delivery may be different: usually by intravenous infusion of a combination of drugs, but also, more simply (more simply for the patient and for the physician, but less simply for the modeller), by oral route when it is possible. Oral delivery implies modelling an absorption compartment, but what follows will be identical: there will be a central (blood) compartment in 
which drugs diffuse and from which they are distributed to their peripheral cellular targets, or will be eliminated under soluble form in the liver or in the kidney, or else will have undesirable side-effects in healthy tissues. Pharmacologists, relying on physiological considerations design ADMET models (see "Whole body physiologically based PK-PD modelling") to deal with the fate of drugs in the organism. Insofar as dynamic processes are considered, compartmental differential equations (usually ordinary differential equations) are used. The control function to be optimised, representing drug delivery, then appears as a positive function (or vector) in the first equation governing plasma drug concentration.

\subsection{General theoretical models}

There is a long tradition in mathematical representation of tumour chemotherapy from various points of view. Dibrov [64, 65], Webb [267], Agur and colleagues [56, 5, 138] have developed the concept of resonance for pulsed chemotherapy, using age-structured PDEs and control theory. Taking advantage of the mathematical observation that periodic chemotherapeutic effects are highest when given at a period equal to, or commensurable with, the cell cycle duration, supposed to be constant in cell populations, they propose optimised chemotherapy principles, with applications in clinical settings, e.g. optimal control of IL21 injection times and doses. Note that this could be taken as a general frame including circadian chronotherapeutics, but there is molecular evidence, as presented earlier here, that chronotherapeutics has other mechanistic grounds.

From a different point of view, using ODEs and optimal control theory, Costa and Boldrini [34, 58, 59] and Kimmel and Swierniak [141] have tackled the problem of drug resistance in cancer cell populations, subdivided in sensitive and resistant subpopulations, to also propose general principles for chemotherapy (not pulsed in general) optimisation, with the objective to reduce the development of the drug resistant subpopulation.

Also from the control scientists' point of view must be mentioned works by J.M. Murray [207], Ledzewicz and Schättler [164], Swan [252, 253]... and others, such as, for drug resistance with a stochastic point of view as well as a continuous one with ODEs, the pioneering work by Goldie and Coldman [113, 114].

These models open interesting mathematical perspectives in different directions, and one should have them in mind when dealing with optimisation of anticancer chemotherapy, even if they do not often consider mechanistic aspects of drug effects on cell populations.

\subsection{Some principles of practical model design for optimisation}

Choosing a model adapted to a specific clinical control problem may completely change the previous theoretical points of view, that quickly show their practical limits. The works reported in the previous section give optimisation principles in rather general settings, and their application is not easy when one is facing questions of combination of anticancer molecules that have completely different action mechanisms. Each therapeutic problem, i.e., tumour type, patient specificities and set of anticancer molecules chosen, is specific and considerations on optimal pulsed therapy or 
bang-bang (i.e., on-off) control shown to be optimal under certain hypotheses may be of little help when one is confronted with a (clinical) therapeutic optimisation problem.

One must also bear in mind that drug delivery time schedules may be completely freely chosen, with existing technological appliances that allow to deliver drugs in the clinic (or in an ambulatory way using portable devices) in a continuous way: programmable pumps endowed with 3-week autonomy, i.e., almost no technological constraint is imposed. The actual modelling framework limits are physiological, not technical.

When designing a pharmacodynamic model with impact on the cell division cycle for therapeutic optimisation, one must deal with a common proliferation model for tumour and healthy tissues (with distinct parameters, but same control targets) if the drugs can affect both. The considered targets are dependent on the drugs in use, that are prescribed by the oncologists according to their pharmacological knowledge and clinical practice, and the action mechanisms of these drugs, i.e., the ways by which they affect the cell division cycle, must be present in the models. As far as possible, all reasons governing the oncologists' choices should be taken into account in working models. The evolution capacity of the tumour toward drug resistance, depending on the drugs in use, and the mechanisms of such possible resistance, should also be documented, in order to design, if relevant, an evolutionary dynamic model of tumour cell proliferation under the mutation pressure induced by the drugs.

\subsection{Practical optimal control problem setting}

What is to be optimised? With what objective function? Under what constraints? These are obvious questions to be asked when defining an optimal control problem.

\subsubsection{Defining optimal therapeutic strategies adapted to different settings}

The control, or input variable to be optimised, i.e., to be the solution of the optimal control problem, is in the most general case a drug infusion flow in the general blood circulation, either directly, by a programmable infusion pump, or via previous intestinal absorption at free or prescribed times and possible transformation. This variable can be a measurable function in e.g., some $L^{2}$ space.

The objective function (the object of the control) must be related to the tumour cell population. A $L^{2}$ or $L^{1}$ average is not very satisfying to consider because it does not exclude hectic behaviour (peaks and troughs) of the tumour cell population that is seldom in accordance with clinical observations. I proposed with C. Basdevant, see [20], to use minimisation of either the absolute minimal tumour cell number (if zero can be reached, then the tumour is eradicated); or the maximal tumour cell number within a given time interval, in the perspective of renewed chemotherapy courses. In the latter case, if this maximal number can be kept below a clinically tolerable threshold, compatible with survival with a good quality of life even if the tumour has not been eradicated, then the treatment may also be considered as successful. The choice between these two strategies is left to the clinician.

Another possible objective function is the growth rate (Malthus exponent) of the tumour cell population; it has not been sufficiently investigated so far. 
The constraints to be considered, in addition to obvious technical ones (limitation of the total infused dose, limitation of the infusion flow gradient) are of two orders (that have usually not been taken into account together so far): a toxicity limitation (unwanted side effects on healthy tissues to be kept below a tolerability threshold) and drug resistance limitation. To these constraints should be added the need to adapt doses to individual patient specificities.

\subsubsection{Limiting toxic side-effects}

The unwanted toxicity limitation may affect different healthy tissues or organs according the particularities of the drugs in use. For instance, in a feasibility study reported in [20,53], a jejunal toxicity limit has been chosen, for it had been shown that in mice (the model parameters had been identified in mice) the jejunum was the most important toxicity target for the drug considered there, oxaliplatin. But it is more frequent to study toxicity effects on the haemotologic bone marrow, as has been done in a few studies with clinical applications [130, 131, 216].

\subsubsection{Minimising drug resistance}

Different mechanisms of resistance to anticancer drugs have been proposed: blocking of cell uptake; modifications, innate or acquired, reversible or not (in concentration levels, in conformational changes) of the drug targets, enhancement of drug detoxification mechanisms, active efflux of drugs from the cell by ABC transporters (P-gp, MDR, MRP, BCRP) [117, 228]. Nevertheless, and unless all cells of a tissue have uniformly the same constitutional characteristics with respect to drug resistance (and then it is only a question of adaptation to individual patients, see next section), this question must be thought of as a cell population rather than a single cell problem. Beyond studies in general population dynamics settings [34, 58, 59, 141], these mechanisms are not always easily representable in ODE models. One can think of at least two different ways of representing the evolution of a cell population towards resistance:

- In a rather classic way, introducing sensitive and resistant subpopulations with possible exchanges between them, a representation by ODE models in cell population dynamics of the resistance mechanisms at work may be considered as a question of balance between two steady states (and bistability with possible hysteresis), with one stable equilibrium representing sensitivity to a given drug, and the other one, resistance. Reversibility may then be present or absent, depending on the shape of a bifurcation diagram in which the bifurcation parameter could be an increasing function of the intracellular drug concentration.

- In another, more recent way, close to cell Darwinism, drug resistance may be seen as a question of adaptive dynamics, where a cell population is structured in a genetic trait and may evolve according to PDE (non local Fisher equation) toward speciation through evolutionary branching. This conception has been developed in general theoretical settings [66, 104, 105, 218], and still remains to be developed in the case of drug resistance representation. It should lead to estimating thresholds of mutation pressure by the drug, in a quantitative manner to be defined in the model in use, below which cancer cells should be contained to avoid emergence of a mutant resistant cell clone. 


\subsubsection{Patient-tailored therapeutics: toward individualised medicine}

As mentioned earlier about genetic polymorphism in drug processing mechanisms, some genetic determinism is present in our cells with respect to intracellular degradation mechanisms, and it has been documented for drugs already mentioned earlier, oxaliplatin and irinotecan [158, 159, 251]. This, in addition to general considerations already mentioned [40,47, 201], shows the way to future patient genotyping before undertaking any chemotherapy, although identified genes with polymorphism known to be responsible for interpatient variability in the response to anticancer drugs are still very few [132]. There is another older story about individualisation of treatments: Isoniazide, that has begun to be used in the treatment of tuberculosis about 60 years ago is degraded in cells by acetylation, and there are "slow" and "fast" acetylers in the general patient population (which is due to different acetylases), and the response to isoniazide shows high interindividual variability: a dose that is toxic in a patient, slow acetyler, will be inefficient in another, fast acetyler. This variability reduces to binary if patients are divided into 2 groups, with respect to their acetylases. In a different context, this is more or less what is expected in the future from patient genotyping in cancer therapy. It is thus a form of "discrete optimisation": according to his or her genotype, a patient should receive a drug dose appropriate to his specific genetic profile.

\section{Concluding remarks and future prospects}

Can mathematics help cure cancer? I have tried to show that the answer is yes. Modelling cell proliferation and drug disposition by continuous time evolution equations can help by:

- studying the theoretical effects of control functions (physiological and pharmacological) on the cell division cycle in cell populations

- proving the feasibility or unfeasibility of proposed therapeutic strategies, under accurate biological theoretical assumptions on the biological framework used;

- proposing optimised multidrug multitargeted therapies according to criteria and constraints defined by the oncologists.

Nevertheless, mathematical modelling and optimisation strategies must be led in close conjunction with clinical oncologists, lest the principles developed in theoretical settings be of little avail to the clinic. To this purpose, it is highly advisable that multidisciplinary teams of scientists, including mathematicians, biologists and pharmacologists, in cancer research centres, work with hospital oncology teams located in a close neighbourhood, and working themselves on specific pathologies. Such situations exist, have yielded interesting results (see e.g. $[88,152,216]$ ) and will hopefully be widely extended in the future.

\section{Acknowledgments}

I thank my colleagues, from the INRIA Bang project-team, particularly Benoit Perthame, without whom cell cycle modelling in cell populations would not have been possible, from the INSERM 
RBC U776 team ("Biologic Rhythms and Cancer"), directed by Francis Lévi, with whom a stimulating collaboration of 10 years has produced theoretical results and projects, some of which designed in European research programs, from Paris XIII University, with Claude Basdevant, who put optimisation of chronotherapy on solid theoretical grounds, and from Lyon I University, with Stéphane Génieys, whose mathematical views on cell Darwinism have played an important role in helping me see cancer evolution and drug resistance as a possible question of adaptive dynamics.

\section{Note on the bibliography}

I apologise for giving a too partial and subjective view on a very vast field. Not only articles relevant to this review, some of them old and classical, others more recent, with an up-to-date list of references, but also classical and more recent books are included to give the reader an opportunity to broaden this view and discover part of the important work that has already been accomplished by many scientists in the past forty years in the three directions sketched in this article: modelling the cell division cycle, modelling pharmacokinetics-pharmacodynamics of anticancer drugs from a mechanistic (physiological) point of view, and designing optimal control algorithms to optimise cancer therapeutics in the clinic.

\section{References}

[1] M. Adimy, F. Crauste. Global stability of a partial differential equation with distributed delay due to cellular replication. Nonlinear Analysis, 54 (2003), No. 8,1469-1491.

[2] M. Adimy, F. Crauste, S. Ruan. A mathematical study of the hematopoiesis process with applications to chronic myelogenous leukemia. SIAM J. Appl. Math., 65 (2005), No. 4,13281352.

[3] M. Adimy, F. Crauste, A. El Abdllaoui. Discrete maturity-structured model of cell differentiation with applications to acute myelogenous leukemia. J. Biological Systems, 16 (2008), No. 3, 395-424.

[4] B.D. Aguda. Modeling the cell division cycle. In A. Friedman (Ed.) Tutorials in Mathematical Biosciences III: Cell Cycle, Proliferation, and Cancer, pp. 1-22. Springer, New York, 2005.

[5] Z. Agur. Mathematical modelling of cancer chemotherapy: Investigation of the resonance phenomenon. In: O. Arino et al. (Ed.). Advances in mathematical population dynamics molecules, cells and man. Papers from the 4th international conference, Rice Univ., Houston, TX, USA, May 23-27, 1995, Ser. Math. Biol. Med. 6 (1997), pp. 571-578, World Scientific, Singapore.

[6] T. Alarcón, H.M. Byrne, P.K. Maini. Towards whole-organ modelling of tumour growth. Prog. Biophys. Mol. Biol., 85 (2004), No. 2-3, 451-72. 
[7] L. Alberghina, H.W. Westerhoff (Eds.). Systems Biology. Definitions and Perspectives. Springer, Berlin, 2005.

[8] B.B. Aldridge, J.M. Burke, D.A. Lauffenburger, P.K. Sorger. Physicochemical modelling of cell signalling. Nature Rev. Mol. Cell Biol., 8 (2006), No. 11, 1195-1203.

[9] A. Altinok, F. Lévi, A. Goldbeter. Identifying mechanisms of chronotolerance and chronoefficacy for the anticancer drugs 5-fluorouracil and oxaliplatin by computational modeling. Eur. J. Pharm. Sci., 36 (2009), No. 1, 20-38.

[10] J.C. Ameisen. La sculpture du vivant. Stock, Paris, 1999.

[11] A.R.A. Anderson, M.A. Chaplain. Chap 10 in L. Preziosi (Ed.). Cancer modelling and simulation, Chapman and Hall, London, 2003.

[12] A.R.A. Anderson, A.M. Weaver, P.T. Cummings, V. Quaranta. Tumor morphology and phenotypic evolution driven by selective pressure from the microenvironment. Cell, 127 (2006), No. 5, 905-915.

[13] A. Aouba, F. Péquignot, A. Le Toullec, E. Jougla. Les causes médicales de décès en France en 2004 et leur évolution / Medical causes of death in France in 2004 and trends 1980-2004 (English abstract). Bulletin épidémiologique hebdomadaire de l'INVS,18 septembre 2007, 35-36. Available on line from http://www.invs.sante.fr/beh/2007/35_36/

[14] O. Arino. A survey of structured cell population dynamics. Acta Biotheor., 43 (1995), No. 1-2, $3-25$.

[15] O. Arino, M. Kimmel. Comparison of approaches to modeling of cell population dynamics. SIAM J. Appl. Math., 53 (1993), No. 5, 1480-1504.

[16] O. Arino, E. Sanchez. A survey of cell population dynamics. J. Theor. Med., 1 (1997), No. 1, $35-51$.

[17] H. Barbason, B. Bouzahzah, C. Herens, J. Marchandise, J. Sulon, J. van Cantfort. Circadian synchronization of liver regeneration in adult rats: the role played by adrenal hormones. Cell Prolif., 22 (1989), No. 6, 451-460.

[18] J. Barnes. The Presocratic philosophers. Paperback edition,1 vol., Routledge, London, 1982.

[19] M.-A. Barrat-Petit, C. Naulin-Ifi, P. Mahler, G. Milano. Dihydropyrimidine déshydrogénase (DPD) : rythme et conséquences. (in French, English summary). Pathol.-Biol., 53 (2005), No. 5, 261-264.

[20] C. Basdevant, J. Clairambault, F. Lévi. Optimisation of time-scheduled regimen for anticancer drug infusion. Mathematical Modelling and Numerical Analysis, 39 (2006), No. 6, 1069-1086. 
[21] B. Basse, B.C. Baguley, E.S. Marshall, W.R. Joseph, B. van Brunt, G. Wake, D.J.N. Wall. A mathematical model for analysis of the cell cycle in cell lines derived from human tumors. $\mathrm{J}$. Math. Biol., 47 (2003), No. 4, 295-312.

[22] F. Bekkal Brikci, J. Clairambault, B. Perthame. Analysis of a molecular structured population model with polynomial growth for the cell cycle. Mathematical and Computer Modelling, 47 (2008), No. 7-8, 699-713.

[23] F. Bekkal Brikci, J. Clairambault, B. Ribba, B. Perthame. An age-and-cyclin-structured cell population model for healthy and tumoral tissues. J. Math. Biol., 57(2008), No. 1, 91-110.

[24] N. Bellomo (Ed.). Selected Topics in Cancer Modeling: Genesis, Evolution, Immune Competition, and Therapy. Birkhäuser, Boston, 2008.

[25] N. Bellomo, M. Delitala. From the mathematical kinetic, and stochastic game theory to modelling mutations, onset, progression and immune competition of cancer cells. Physics of Life Reviews, 5 (2008), No. 4, 183-206.

[26] Y. Ben-Neriah, G.Q. Daley, A.M. Mes-Masso, O.N. Witte, D. Baltimore. The chronic myelogenous leukemia-specific p210 protein is the product of the BCR/ABL hybrid gene. Science, 233 (1986), No. 4760 , 212-214.

[27] S. Bernard, HP. Herzel. Why do cells cycle with a 24 h period? Genome Informatics, 17 (2006), No. 1, 72-79.

[28] S. Bernard, J. Bélair, M.C. Mackey. Oscillations in cyclical neutropenia: New evidence based on mathematical modeling. J. Theor. Biol., 223 (2003), No. 3, 283-298.

[29] N. Bessonov, A. Ducrot, V. Volpert. Modeling of leukemia development in the bone marrow. Proc. of the annual Symposium on Mathematics applied in Biology and Biophysics, Tome XLVIII (2005), vol. 2, 79-88.

[30] N. Bessonov, I. Demin, L. Pujo-Menjouet, V. Volpert. A multi-agent model describing selfrenewal of differentiation effects on the blood cell population. Mathematical and computer modelling, 49 (2009), No. 11-12, 2116-2127.

[31] M. Bizzarri, A. Cucina, F. Conti, F. D’Anselmi. Beyond the Oncogene Paradigm: Understanding the Complexity in Cancerogenesis. Acta Biotheor., 56 (2008), No. 3, 173-196.

[32] G.A. Bjarnason, R.C.K. Jordan, R.C.K., R.B. Sothern. Circadian variation in the expression of cell-cycle proteins in the human oral epithelium. Am. J. Pathol., 154 (1999), No. 2, $613-$ 622.

[33] M.V. Blagosklonny, A. Pardee. The restriction point of the cell cycle. Cell Cycle, 1 (1974), No. 2, 103-110. 
[34] J.L. Boldrini, M.I.S. Costa. Therapy burden, drug resistance, and optimal treatment regimen for cancer therapy. IMA J. Math. Appl. Med. Biology, 17 (2000), No. 1, 33-51.

[35] N.A. Boughattas, F. Lévi, et al. Circadian Rhythm in Toxicities and Tissue Uptake of 1,2-diamminocyclohexane(trans-1)oxaloplatinum(II) in Mice. Cancer Research, 49 (1989), No. 12, 3362-3368.

[36] K. Boushaba, H.A. Levine, M. Nilsen-Hamilton. A mathematical model for the regulation of tumor dormancy based on enzyme kinetics. Bull. Math. Biol., 68 (2006), No. 7, 1495-1526.

[37] L. Bourgey. Observation et expérience chez Aristote. Vrin, coll. Bibliothèque d'Histoire de la Philosophie, Paris, 1955.

[38] M. Breccia, G. Alimena. Resistance to imatinib in chronic myeloid leukemia and therapeutic approaches to circumvent the problem. Cardiovasc. Hematol. Disord. Drug Targets, 9 (2009), No. 1, 21-28.

[39] N.F. Britton. Reaction-diffusion equations and their applications to biology. Academic Press, London, 1986

[40] M.P. Brynildsen, J.J. Collins. Systems biology makes it personal. Mol. Cell, 34 (2009), No. 1, 137-138.

[41] F.J. Burns, I.F. Tannock. On the existence of a $G_{0}$ phase in the cell cycle. Cell Tissue Kinet., 19 (1970), No. 4, 321-334.

[42] H.M. Byrne, D. Drasdo. Individual-based and continuum models of growing cell populations: a comparison. J. Math. Biol., 58 (2009), No. 4-5, 657-87.

[43] L. Calzone, S. Soliman. Coupling the cell cycle and the circadian cycle. INRIA internal research report \#5835 (2006). Available online from http://hal.inria.fr/INRIA-RRRT.

[44] A. Cappuccio, M.A. Herrero, L. Nunez. Biological optimization of tumor radiosurgery. Med Phys., 36 (2009), No. 1, 98-104.

[45] N. Champagnat, R. Ferrière, S. Méléard. Unifying evolutionary dynamics: From individual stochastic processes to macroscopic models. Theoretical Population Biology, 69 (2006), No. 3, 297-321.

[46] S.G. Chaney, S.L. Campbell, E. Bassett, Y.B. Wu. Recognition and processing of cisplatinand oxaliplatin-DNA adducts. Clin. Rev. Oncol. Hematol., 53 (2003), No. 1, 3-11.

[47] J.T. Chang, C. Carvalho, S. Mori S, A.H. Bild, M.L. Gatza, Q. Wang Q, J.E. Lucas JE, A. Potti, P.G. Febbo, M. West, J.R. Nevins. A genomic strategy to elucidate modules of oncogenic pathway signaling networks. Mol. Cell, 34 (2009), No.1, 104-14. 
[48] G. Chiorino, J.A.J. Metz, D. Tomasoni, P. Ubezio. Desynchronization rate in cell populations: mathematical modeling and experimental data. J. Theor. Biol., 208 (2001), No.2, 185199.

[49] A. Ciliberto, M.J. Petrus, J.J. Tyson, J.C. Sible. A kinetic model of the cyclin E/Cdk2 developmental timer in Xenopus laevis embryos. Biophys. Chem., 104 (2003), No. 3, 573-89.

[50] A. Ciliberto, B. Novak, J.J. Tyson. Steady states and oscillations in the p53/Mdm2 network. Cell Cycle, 4 (2005), No. 3, 488-493.

[51] J. Clairambault. A step toward optimization of cancer therapeutics. Physiologically based modelling of circadian control on cell proliferation. IEEE-EMB Magazine, 27 (2008), No.1, $20-24$.

[52] J. Clairambault, S. Gaubert, B. Perthame. An inequality for the Perron and Floquet eigenvalues of monotone differential systems and age structured equations. C. R. Acad. Sci. (Paris) Ser. I Mathématique, 345 (2007), No. 10, 549-554.

[53] J. Clairambault. Modelling oxaliplatin drug delivery to circadian rhythm in drug metabolism and host tolerance. Advanced Drug Delivery Reviews (ADDR), 59 (2007), No. 9-10, 1054 1068 .

[54] J. Clairambault, P. Michel, B. Perthame. A model of the cell cycle and its circadian control. In: Mathematical Modeling of Biological Systems, Volume I: Cellular Biophysics, Regulatory Networks, Development, Biomedicine, and Data Analysis, Deutsch, A., Brusch, L., Byrne, H., de Vries, G., Herzel, H. (Eds.), Birkhäuser, Boston, pp. 239-251, 2007.

[55] J. Clairambault, P. Michel, B. Perthame. Circadian rhythm and tumour growth. C. R. Acad. Sci. (Paris) Mathématique (Équations aux dérivées partielles), 342 (2006), No. 1, 17-22.

[56] L. Cojocaru, Z. Agur. A theoretical analysis of interval drug dosing for cell-cycle-phasespecific drugs. Math. BioSci., 109 (1992), No 1, 85-97.

[57] C. Colijn, M.C. Mackey. A mathematical model of hematopoiesis: I. Periodic chronic myelogenous leukemia. J. Theor. Biol., 237 (2005), No. 2, 117-132.

[58] M.I.S Costa, J.L. Boldrini. Chemotherapeutic treatments: a study of the interplay among drug resistance, toxicity and recuperation from side effects. Bull. Math. Biol., 59 (1997), No. 2, 205-232.

[59] M.I.S. Costa, J.L. Boldrini. Conflicting objectives in chemotherapy with drug resistance. Bull. Math. Biol., 59 (1997), No. 4, 707-724.

[60] C. Csajka, D. Verotta. Pharmacokinetic-pharmacodynamic modelling: history and perspectives. J. Pharmacokinet. Pharmacodyn., 33 (2006), No. 3, 227-79. 
[61] A. Csikasz Nagy, D. Battogtokh, K.C. Chen, B. Novak, J.J. Tyson. Analysis of a generic model of eukaryotic cell-cycle regulation. Biophys J., 90 (2006), No. 12, 4361-79.

[62] R. Dautray, J.-L. Lions. Mathematical analysis and numerical methods for sciences and technology. Ch. VIII, 187-199, Springer, Berlin,1990.

[63] T. David-Pfeuty. The flexible evolutionary anchorage-dependent Pardee's restriction point of mammalian cells: how its deregulation may lead to cancer. Biochim Biophys Acta., 1765 (2006), No. 1, 38-66.

[64] B.F. Dibrov, A.M. Zhabotinsky, Yu.A. Neyfakh, M.P. Orlova, L.I. Churikova. Optimal scheduling for cell synchronization by cycle-phase-specific blockers. Math. BioSci., 66 (1983), No. 2, 167-185.

[65] B.F. Dibrov, A.M. Zhabotinsky, Yu.A. Neyfakh, M.P. Orlova, L.I. Churikova. Mathematical model of cancer chemotherapy. Periodic schedules of phase-specific cytotoxic-agent administration increasing the selectivity of therapy. Math. BioSci., 73 (1985), No. 1, 1-31.

[66] O. Diekmann, P.E. Jabin, S. Mischler, B. Perthame. The dynamics of adaptation: an illuminating example and a Hamilton-Jacobi approach. Theoretical Population Biology, 67 (2005), No. 4, 257-271.

[67] L. Dimitrio. Irinotecan: Modelling intracellular pharmacokinetics and pharmacodynamics, M2 master thesis (in French, English summary). University Pierre-et-Marie-Curie and INRIA internal report, June 2007.

[68] D. Dingli, A. Traulsen, J.M. Pacheco. Stochastic dynamics of hematopoietic tumor stem cells. Cell Cycle, 6 (2007), No. 4, 461-466.

[69] D. Dingli, A. Traulsen, F. Michor. (A)symmetric stem cell replication and cancer. PLoS Comput. Biol., 2007, Mar 16;3(3):e53. [doi:10.1371/journal.pcbi.0030053].

[70] D. Dingli, A. Traulsen, J.M. Pacheco. Compartmental architecture and dynamics of hematopoiesis. PLoS One, 2007, Apr. 4, 2(4): e345. [doi:10.1371/journal.pone.0000345].

[71] D. Dingli, J.M. Pacheco. Some dynamic aspects of hematopoietic stem cells. Stem Cell Rev., 4 (2008), No. 1, 57-64.

[72] D. Dingli, T. Antal, A. Traulsen, J.M. Pacheco. Progenitor self-renewal and cyclical neutropenia. Cell Prolif., 42 (2009), No. 3, 330-338.

[73] M. Doumic-Jauffret. Analysis of a population model structured by the cells molecular content. Mathematical Modelling of Natural Phenomena, 2 (2007), No. 3, 121-15.

[74] D. Drasdo, S. Höhme, M. Block. On the Role of Physics in the Growth and Pattern Formation of Multi-Cellular Systems: What can we Learn from Individual-Cell Based Models? J. Stat. Phys.,128 (2007), No. 1-2, 287-345. 
[75] B.J. Druker, et al. Effects of a selective inhibitor of the Abl tyrosine kinase activity on the growth of BCR-ABL positive cells. Nature Med., 2 (1996), No. 5, 561-566.

[76] B.J. Druker, et al. Efficacy and safety of a specific inhibitor of the BCR-ABL tyrosine kinase in chronic myeloid leukemia. N. Engl. J. Med., 344 (2001), No. 14, 1031-1037.

[77] A. Ducrot, V. Volpert. On a model of leukemia development with a spatial cell distribution. Mathematical Modelling of Natural Phenomena, 2 (2007), No. 3, 101-120.

[78] M. Eisen. Mathematical models in cell biology and cancer chemotherapy. Lectures Notes in Biomathematics 30, Springer, Berlin, 1979.

[79] M. Elshaikh, M. Ljungman, R. Ten Haken, A.S. Lichter. Advances in Radiation Oncology. Annu. Rev. Med., 57 (2006),19-31.

[80] S. Faivre, D. Chan, R. Salinas, B. Woynarowska, J.M. Woynarowski. DNA strand breaks and apoptosis induced by oxaliplatin in cancer cells. Biochemical pharmacology, 66 (2003), No. 2, 225-237.

[81] E. Fearon, B. Vogelstein. A genetic model for colorectal tumorigenesis. Cell, 61 (1990), No. 5, 759-67.

[82] J.E. Ferrell Jr. Tripping the switch fantastic: how a protein kinase cascade can convert graded inputs into switch-like outputs. Trends Biochem. Sci., 21 (1996), No. 12, 460-466.

[83] J.E. Ferrell Jr. How responses get more switch-like as you move down a protein kinase cascade. Trends Biochem. Sci., 22 (1997), No. 8, 288-289.

[84] E. Filipski, V.M. King, X.M. Li, T.G. Granda, F. Lévi. Host circadian clock as a control point in tumor progression. J. Natl. Cancer Inst., 94 (2002), No. 9, 690-697.

[85] E. Filipski, P.F. Innominato, M.W. Wu, X.M. Li, S. Iacobelli, L.J. Xian, F. Lévi. Effect of light and food schedules on liver and tumor molecular clocks in mice. J. Natl. Cancer Inst., 97 (2005), No. 7, 507-517.

[86] G. Finak, N. Bertos, F. Pepin, S. Sadekova, M. Souleimanova, H. Zhao, H. Chen, G. Omeroglu, S. Meterissian, A. Omeroglu, M. Hallett, M. Park. Stromal gene expression predicts clinical outcome in breast cancer. Nature Med., 14 (2008), No. 5, 518-527.

[87] B. Finkenstädt, E.A. Heron, M. Komorowski, K. Edwards, S. Tang, C.V. Harper CV, J.R. Davis, M.R. White, A.J. Millar, D.A. Rand. Reconstruction of transcriptional dynamics from gene reporter data using differential equations. Bioinformatics, 24 (2008), No. 24, 2901-2907.

[88] K.R. Fister, J.C. Panetta. Optimal control applied to cell-cycle-specific cancer chemotherapy. SIAM J. Appl. Math., 60 (2000), No. 3, 1059-1072. 
[89] C. Foley, S. Bernard, M.C. Mackey. Cost-effective G-CSF therapy strategies for cyclical neutropenia: Mathematical modelling based hypotheses. J. Theor. Biol., 238 (2006), No. 4, 754-763.

[90] C. Foley, M.C. Mackey. Dynamic hematological disease: a review. J. Math. Biol., 58 (2009), No. 1-2, 285-322.

[91] C. Foley, M.C. Mackey. Mathematical model for G-CSF administration after chemotherapy. J. Theor. Biol., 257 (2009), No. 1, 27-44.

[92] D.B. Forger, M.E. Jewett, R.E. Kronauer. A simpler model of the human circadian pacemaker. J. Biol .Rhythms, 14 (1999), No. 6, 532-7.

[93] D.B. Forger, R.E. Kronauer. Reconciling mathematical models of biological clocks by averaging on approximate manifolds. SIAM J. Appl. Math., 62 (2002), No. 4, 1281-1296.

[94] D.B. Forger, C.S. Peskin. A detailed predictive model of the mammalian circadian clock. Proc. Natl. Acad. Sci. USA, 100 (2003), No. 25, 14806-14811.

[95] D.B. Forger, D.A. Dean 2nd, K. Gurdziel, J.-C. Leloup, C. Lee, C. Von Gall, J.P. Etchegaray, R.E. Kronauer, A. Goldbeter, C.S. Peskin, M.E. Jewett, D.R. Weaver. Development and validation of computational models for mammalian circadian oscillators. OMICS, 7 (2003), No. 4, 387-400.

[96] S. A. Frank. Dynamics of Cancer. Incidence, Inheritance and evolution. Princeton university Press, Princeton, 2007.

[97] A. Friedman (Ed.). Cell Cycle, Proliferation, and Cancer. Tutorials in Mathematical Biosciences III, Lecture Notes in Mathematics 1872 / Mathematical Biosciences Subseries, Springer, New York, 2006.

[98] L. Fu, H. Pelicano, J. Liu, P. Huang, C.C. Lee. The circadian gene Per2 plays an important role in tumor suppression and DNA damage response in vivo. Cell, 111 (2002), No. 1, 41-50.

[99] L. Fu, L., C.C. Lee. The circadian clock: pacemaker and tumor suppressor. Nature Rev. Cancer, 3 (2003), No. 5, 350-361.

[100] J. Galle, G. Aust, G. Schaller, T. Beyer, D. Drasdo. Individual cell-based models of the spatio-temporal organisation of multicellular systems - achievements and limitations. $\mathrm{Cy}-$ tometry A, 69A (2006), No. 7, 704-710.

[101] R.A. Gatenby, E.T. Gawlinski. A reaction-diffusion model of cancer invasion. Cancer Res., 56 (1996), No. 24, 745-53.

[102] R.A. Gatenby, E.T. Gawlinski. The glycolytic phenotype in carcinogenesis and tumor invasion: insights through mathematical models. Cancer Res., 63 (2003), No. 14, 3847-54. 
[103] R.A. Gatenby, R.J. Gillies. A microenvironmental model of carcinogenesis. Nature Rev. Cancer, 8 (2008), No. 1, 56-61.

[104] S. Génieys, V. Volpert, P. Auger. Adaptive dynamics: modelling Darwin's divergence principle. C. R. Acad. Sci. Paris Biologie, 329 (2006), No. 11, 876-879.

[105] S. Génieys, N. Bessonov, V. Volpert. Mathematical model of evolutionary branching. Mathematical and Computer Modelling, 49 (2009), No. 11-12, 2109-2115.

[106] A. Gerisch, M.A. Chaplain. Mathematical modelling of cancer cell invasion of tissue: local and non-local models and the effect of adhesion. J. Theor. Biol., 250 (2008), No. 4, 684-704.

[107] N. Geva-Zatorsky, N. Rosenfeld, S. Itzkovitz, R. Milo, A. Sigal, E. Dekel, T. Yarnitzky, Y. Liron, P. Polak, G. Lahav, U. Alon. Oscillations and variability in the p53 system. Mol. Syst. Biol., 2 (2006), 2:2006.0033. Epub 2006 Jun 13. [doi:10.1038/msb4100068].

[108] D. Gholam, S. Giacchetti, C. Brézault-Bonnet, M. Bouchahda, D. Hauteville, R. Adam, B. Ducot, O. Ghémard, F. Kustlinger, C. Jasmin, F. Lévi. Chronomodulated irinotecan, oxaliplatin, and leucovorin-modulated 5-Fluorouracil as ambulatory salvage therapy in patients with irinotecan- and oxaliplatin-resistant metastatic colorectal cancer. Oncologist, 11 (2006), No. 10, 1072-80.

[109] A. Goldbeter, D.E. Koshland Jr. An amplified sensitivity arising from covalent modification in biological systems. Proc. Natl. Acad. Sci. USA, 78 (1981), No. 11, 6840-4.

[110] A. Goldbeter. A minimal cascade model for the mitotic oscillator involving cyclin and cdc2 kinase. Proc. Natl. Acad. Sci. USA, 88 (1991), No. 20, 9107-11.

[111] A. Goldbeter. A model for circadian oscillations in the Drosophila period protein (PER). Proc Roy. Soc. B (Biol. Sci.) 261 (1995), No. 1362, 319-324.

[112] A. Goldbeter. Biochemical oscillations and cellular rhythms. Cambridge University Press, 1996.

[113] J.H. Goldie, A.J. Coldman. A mathematical model for relating the drug sensitivity of tumors to their spontaneous mutation rate. Canc. Treat. Rep., 63 (1979), No. 11-12, 1727-1733.

[114] J.H. Goldie, A.J. Coldman. Drug Resistance in Cancer: Mechanisms and Models. Cambridge University Press, 1998.

[115] B.C. Goodwin. Temporal organization in cells: a dynamic theory of cellular control processes. Academic Press, New York, 1963.

[116] B.C. Goodwin. Oscillatory behavior in enzymatic control processes. In: Advances in enzyme regulation, vol. 3 (G. Weber, Ed.), pp. 425-438, Pergamon Press, Oxford, 1965. 
[117] M.M. Gottesmann, T. Fojo, S.E. Bates. Multidrug resistance in cancer: Role of ABC transporters. Nature Rev. Cancer, 2 (2002), No. 1, 48-58.

[118] T. Granda, X.H. Liu, R. Smaaland, N. Cermakian, E. Filipski, P. Sassone-Corsi, F. Lévi. Circadian regulation of cell cycle and apoptosis in mouse bone marrow and tumor. FASEB J., 19 (2005), No. 2, 304-306.

[119] M. Gyllenberg, G. Webb. Quiescence as an explanation of Gompertzian tumor growth. Growth Dev. Aging, 153 (1989), No. 1-2, 25-33.

[120] M. Gyllenberg, G. Webb. A nonlinear structured population model of tumor growth with quiescence. J. Math. Biol., 28 (1990), No. 6, 671-94.

[121] T. Haferlach. Molecular genetic pathways as therapeutic targets in AML. In: Educational book, ASH 2008 meeting, pp. 400-411, 2008.

[122] D. Hanahan, R.A. Weinberg. The hallmarks of cancer. Cell, 100 (2000), No. 1, 57-70.

[123] J.C. Harrison, J.E. Haber. Surviving the breakup; the DNA damage checkpoint. Annu. Rev. Genet., 40 (2006), 209-235.

[124] C. Haurie, D.C. Dale, M.C. Mackey. Cyclical neutropenia and other periodic hematological diseases: A review of mechanisms and mathematical models. Blood, 92 (1998), No. 8, 26292640 .

[125] R. Heinrich, S. Schuster. The regulation of cellular systems. Chapman and Hall, New York, 1996.

[126] E.A. Heron, B. Finkenstädt, D.A. Rand. Bayesian inference for dynamic transcriptional regulation; the Hes 1 system as a case study. Bioinformatics, 23 (2007), No. 19, 2596-603.

[127] P. Hinow, S.E. Wang, C.L. Arteaga, G.F. Webb. A mathematical model separates quantitatively the cytostatic and cytotoxic effects of a HER 2 tyrosine kinase inhibitor. Theor. Biol. Med. Modelling, (2007). [doi:10.1186/1742-4682-4-14.]

[128] M. Hollstein, D. Sidransky, B. Vogelstein, C.C. Harris. p53 mutations in human cancers. Science, 253 (1991), No. 5015, 49-53.

[129] P.J. Houghton, G.S. Germain, F.C. Harwood, J.D. Schuetz, C.F. Stewart, E. Buchdunger, P. Traxler. Imatinib mesylate is a potent inhibitor of the ABCG2 (BCRP) transporter and reverses resistance to Topotecan and SN-38 in vitro. Canc. Res., 64 (2004), No. 7, 23332337.

[130] A. Iliadis, D. Barbolosi. Optimizing drug regimens in cancer chemotherapy by an efficacytoxicity mathematical model. Computers Biomed. Res., 33 (2000), No. 3, 211-226. 
[131] A. Iliadis, D. Barbolosi. Optimising drug regimens in cancer chemotherapy: a simulation study using a PK-PD model. Computers Biol. Med., 31 (2001), No. 3, 157-172.

[132] F. Innocenti, D.L. Kroetz, E. Schuetz, M.E. Dolan, J. Ramirez, M. Relling, P.X. Chen, S. Das, G.L. Rosner, M.J. Ratain. Comprehensive pharmacogenetic analysis of Irinotecan neutropenia and pharmacokinetics. J. Clin. Oncol., (2009), Apr. 6 [Epub ahead of print]. [doi: 10.1200/JCO.2008.20.6300].

[133] T.L. Jackson, H.M. Byrne. A mathematical model to study the effects of drug resistance and vasculature on the response of solid tumors to chemotherapy. Math. Biosci., 164 (2000), No. 1, 17-38.

[134] A. Jemal, R. Siegel, E. Ward, T. Murray, J.Q. Xu, M.J. Thun. Cancer Statistics, 2007. CA Cancer J. Clin., 57 (2007), No. 1, 43-66.

[135] B. Kang, Y.Y. Li, X. Chang, L. Liu, Y.X. Li. Modeling the effects of cell cycle Mphase transcriptional inhibition on circadian oscillation. PLoS Comput. Biol., (2008). [doi: 10.1371/journal.pcbi.1000019].

[136] M.B. Kastan, J. Bartek. Cell-cycle checkpoints and cancer. Nature, 432 (2004), No. 7015, $316-323$.

[137] J.P. Keener, J. Sneyd. Mathematical physiology. Springer, New York, 1998.

[138] Yu. Kheifetz, Yu. Kogan, Z. Agur. Long-range predictability in models of cell populations subjected to phase-specific drugs: Growth-rate approximation using properties of positive compact operators. Math. Models Meth. Appl. Sci., 16 (2006), No. 7, 1-18.

[139] P.S. Kim, P.P. Lee, D. Levy. Modeling Imatinib-treated chronic myelogenous leukemia: reducing the complexity of agent-based models. Bull. Math. Biol. 70 (2008), No. 3, 728-744.

[140] P.S. Kim, P.P. Lee, D. Levy. A PDE model for Imatinib-treated chronic myelogenous leukemia. Bull. Math. Biol. 70 (2008), No. 7, 1994-2016.

[141] M. Kimmel, A. Swierniak. Control theory approach to cancer chemotherapy: Benefiting from phase dependence and overcoming drug resistance. In: Cell cycle, proliferation, and cancer (A. Friedman, Ed.), Springer LN 1872, pp. 185-216, Springer, New York, 2006.

[142] H. Kitano (Ed.). Foundations of Systems Biology. MIT Press, Cambridge (MA), 2001.

[143] H. Kitano. Computational systems biology. Nature, 420 (2002), No. 6912, 206-210.

[144] H. Kitano. Cancer as a robust system: Implications for anticancer therapy. Nature Rev. Cancer, 4 ( 2004), No. 3, 227-235.

[145] H. Kitano. A robustness-based approach to systems-oriented drug design. Nature Rev. Drug Discovery, 6 (2007), No. 3, 202-210. 
[146] M. Kivisaar. Stationary phase mutagenesis: mechanisms that accelerate adaptation of microbial populations under environmental stress. Environm. Microbiol., 5 (2003), No. 10, 814-827.

[147] M. von Kleist, W. Huisinga. Physiologically based pharmacokinetic modelling: a subcompartmentalized model of tissue distribution. J Pharmacokinet Pharmacodyn., 34 (2007), No. 6, 789-806.

[148] A.G. Knudson. Two genetic hits (more or less) to cancer. Nature Rev. Cancer, 1 (2001), No. 2, 157-162.

[149] K. Kohn. Molecular interaction map of the mammalian cell cycle control and DNA repair systems. Mol. Biol. Cell, 10 (1999), No. 8, 2703-34.

[150] K.W. Kohn, M.I. Aladjem, S. Kim, J.N. Weinstein, Y. Pommier. Depicting combinatorial complexity with the molecular interaction map notation. Mol. Sys. Biol., 51 (2006), 1-12. [doi:10.1038/msb4100088].

[151] K.W. Kohn, M.I. Aladjem, J.N. Weinstein, Y. Pommier. Molecular interaction maps of bioregulatory networks: a general rubric for systems biology. Mol. Biol. Cell, 17 (2006), No. 1, 1-13.

[152] F. Kozusko, P.H. Chen, S.G. Grant, B.W. Day, J.C. Panetta. A mathematical model of in vitro cancer cell growth and treatment with the antimitotic agent curacin A. Math. Biosci., 170 (2001), No. 1, 1-16.

[153] F. Kozusko, Z. Bajzer. Combining Gompertzian growth and cell population dynamics. Math. Biosci., 185 (2003), No. 2, 153-67.

[154] A. Kramer, F.C. Yang, P. Snodgrass, X. Li, T.E. Scammell. Regulation of daily locomotor activity and sleep by hypothalamic EGF receptor signaling. Science, 294 (2001), No. 5551, 2511-15.

[155] J.-J. Kupiec. A Darwinian theory for the origin of cellular differentiation. Molecular and General Genetics, 255 (1997), No. 2, 201-208.

[156] J.-J. Kupiec, P. Sonigo. Ni Dieu ni gène. Pour une autre théorie de l'hérédité. Seuil, Paris, 2000.

[157] J.-J. Kupiec. L’origine des individus. Fayard, Paris, 2008.

[158] D.M. Kweekel, H. Gelderblom, H.-J. Guchelaar. Pharmacology of oxaliplatin and the use of pharmacogenomics to individualize therapy. Canc. Treat. Rev., 31 (2005), No.2, 90-105.

[159] D.M. Kweekel, H. Gelderblom, H.-J. Guchelaar. Clinical and pharmacogenetic factors associated with irinotecan toxicity. Canc. Treat. Rev., 34 (2008), No. 7, 655-669. 
[160] E. Laconi. The evolving concept of tumor microenvironments. Bioessays, 29 (2007), No. 8, 738-44.

[161] G. Lahav, N. Rosenfeld, A. Sigal, N. Geva-Zatorsky, A.J. Levine, M.B. Elowitz, U. Alon. Dynamics of the p53-Mdm2 feedback loop in individual cells. Nature Genet., 36 (2004), No. 2, 147-150.

[162] L.G. Lajtha. On DNA labeling in the study of the dynamics of bone marrow cell populations. In: Stohlman, Jr., F. (Ed), The Kinetics of Cellular Proliferation, pp. 173-182, Grune and Stratton, New York, 1959.

[163] J.L. Lebowitz, S.I. Rubinow. A theory for the age and generation time distribution of a microbial population. J. Math. Biol., 1 (1974), No. 1, 17-36.

[164] U. Ledzewicz, H. Schättler. Structure of optimal controls for a cancer chemotherapy model with PK/PD. In: Proceedings of the 43rd Conference on Decision and Control, Atlantis, Bahamas islands, pp. 1376-1381, IEEE Publishing, 2004.

[165] J.-C. Leloup, D. Gonze, A. Goldbeter. Limit cycle models for circadian rhythms based on transcriptional regulation in Drosophila and Neurospora. J. Biol. Rhythms, 14 (1999), No. 6 , 433-448.

[166] J.-C. Leloup, A. Goldbeter. Towards a detailed computational model for the mammalian circadian clock. Proc. Natl. Acad. Sci. USA, 100 (2003), No. 12, 7051-7056.

[167] F. Lévi (Ed.). Cancer chronotherapeutics. Special issue of Chronobiology International, Vol. 19 (2002), No. 1.

[168] F. Lévi. Chronotherapeutics: the relevance of timing in cancer therapy. Cancer Causes Control, 17 (2006), No. 4, 611-621.

[169] F. Lévi, G. Metzger, C. Massari, G. Milano. Oxaliplatin: Pharmacokinetics and Chronopharmacological Aspects. Clin. Pharmacokinet., 38 (2000), No. 1, 1-21.

[170] F. Lévi , U. Schibler. Circadian Rhythms: Mechanisms and Therapeutic Implications. Ann. Rev. Pharmacol. Toxicol., 47 (2007), 493-528.

[171] F. Lévi, A. Altinok, J. Clairambault, A. Goldbeter. Implications of circadian clocks for the rhythmic delivery of cancer therapeutics. Phil. Trans. Roy. Soc. A, 366 (2008), No. 1880, 3575-3598.

[172] A.J. Levine, J. Momand, C.A. Finlay. The p53 tumor suppressor gene. Nature, 351 (1991), No. 6326, 453-456.

[173] M. Loeffler, I. Roeder. Tissue stem cells: definition, plasticity, heterogeneity, selforganization and models - A conceptual approach. Cells Tissues Organs, 171 (2002), No. 1, $8-26$. 
[174] X.M. Li, G. Metzger, E. Filipski, N. Boughattas, G. Lemaigre, B. Hecquet., E. Filipski, F. Lévi. Pharmacologic modulation of reduced glutathione circadian rhythms with buthionine sulfoximine: relationship with cisplatin toxicity in mice. Tox. Appl. Pharmacol., 143 (1997), No. 2, 281-290.

[175] X.M. Li, G. Metzger, E. Filipski, G. Lemaigre, F. Lévi. Modulation of nonprotein sulphydryl compounds rhythm with buthionine sulphoximine: relationship with oxaliplatin toxicity in mice. Arch.Toxicol., 72 (1998), No. 9, 574-579.

[176] D.B. Longley, D.P. Harkin, P.G. Johnston. 5-Fluorouracil: mechanisms of action and clinical strategies. Nature Rev. Cancer, 3 (2003), No. 5, 330-338.

[177] R.A. Lockshin, Z. Zakeri, J.L. Tilly (Eds.). When cells die. Wiley, New York, 1998.

[178] R.A. Lockshin, Z. Zakeri (Eds.). When cells die II. Wiley, New York, 2004.

[179] H. Lodish. Ed. Molecular Cell Biology. Freeman, New York, 2003.

[180] T.G. Lugo, A.M. Pendergast, A.J. Muller, O.N. Witte. Tyrosine kinase activity and transformation potency of BCR-ABL oncogene products. Science, 247 (1990), No. 4946, 1079-1082.

[181] A.G. McKendrick. Applications of mathematics to medical problems. Proc. Edinburgh Math. Soc., 54 (1926), 98-130.

[182] M.C. Mackey. Unified Hypothesis for the Origin of Aplastic Anemia and Periodic Hematopoiesis. Blood, 51 (1978), No. 5, 941-956.

[183] M.C. Mackey. Dynamic hematological disorders of stem cell origin. In: G. VassilevaPopova and E.V. Jensen (Eds). Biophysical and Biochemical Information Transfer in Recognition, pp. 373-409, Plenum Press, New York, 1979.

[184] M.C. Mackey, R. Rudnicki. Global stability in a delayed partial differential equation describing cellular replication. J. Math. Biol., 33 (1994), No. 1, 89-109.

[185] M.C. Mackey, R. Rudnicki.. A new criterion for the global stability of simultaneous cell replication and maturation process. J. Math. Biol., 38 (1999),195-219.

[186] M.C. Mackey. Cell kinetic status of haematopoietic stem cells. Cell Prolif., 34 (2001), No. 2 , 71-83.

[187] P. Macklin, S. McDougall, A.R.A Anderson, M.A. Chaplain, V. Cristini, J. Lowengrub. Multiscale modelling and nonlinear simulation of vascular tumour growth. J. Math. Biol., 58 (2009), No. 4-5, 765-98.

[188] M.V. Maffini, J.M. Calabro, A.M. Soto, C. Sonnenschein. Stromal regulation of neoplastic development. Age-dependent normalization of neoplastic mammary cells by mammary stroma. Am. J. Pathol., 167 (2005), No. 5, 1405-1410. 
[189] P. Magal, S.G. Ruan (Eds.). Structured population models in biology and epidemiology. Springer LN in Mathematics 1936, Springer, New York, 2008.

[190] P. Magni, M. Simeoni, I. Poggesi, M. Rocchetti. A mathematical model to study the effects of drugs administration on tumor growth dynamics. Math. Biosci., 200 (2006), No. 2, 127-51.

[191] M. Malumbres, M. Barbacid. To cycle or not to cycle: a critical decision in cancer. Nature Rev. Cancer, 1 (2001), No. 3, 222-231.

[192] A. Marciniak-Czochra, T. Stiehl, A.D. Ho, W. Jäger, W. Wagner. Modeling of asymmetric cell division in hematopoietic stem cells - Regulation of self-renewal is essential for efficient repopulation. Stem Cells Dev., 18 (2009), No. 3, 57-66.

[193] J. Massagué. G1 cell-cycle control and cancer. Nature, 432 (2004), No. 7015, 298-306.

[194] T. Matsuo, S. Yamaguchi, S. Mitsui, A. Emi, F. Shimoda, H. Okamura. Control mechanism of the circadian clock for timing of cell division in vivo. Science, 302 (2003), No. 5643, 255-259.

[195] L. Mazelin, A. Bernet, C. Bonod-Bidaud, L. Pays, S. Arnaud, C. Gespach, D.E. Bredesen, J.-Y. Scoazec, P. Mehlen. Netrin-1 controls colorectal tumorigenesis by regulating apoptosis. Nature, 431 (2004), No. 7004, 80-4.

[196] P. Mehlen, C. Thibert. Dependence receptors: between life and death. Cell Mol Life Sci., 61 (2004), No. 15, 1854-66.

[197] S. Méléard, V.C. Tran. Trait substitution sequence processes and canonical equation for age-structured populations. J. Math. Biol., 58 (2009), No. 6, 881-921.

[198] J. Mendelsohn, J. Baselga. Status of Epidermal Growth Factor Receptor Antagonists in the Biology and Treatment of Cancer. J. Clin. Oncol., 21 (2003), No. 14, 2787-2799.

[199] J.A.J. Metz, O. Diekmann. The dynamics of physiologically structured populations. LN in biomathematics 68, Springer, New York, 1986.

[200] P. Michel, S. Mischler, B. Perthame. The entropy structure of models of structured population dynamics. General relative entropy inequality: an illustration on growth models. J. Math. Pures et Appl., 84 (2005), No. 9, 1235-1260.

[201] G. Milano, J. Robert. Pharmaco génétique - pharmacogénomie, quelle est la différence ? Oncologie, 7 (2005), No. 1, 4-5.

[202] S. Mischler, B. Perthame, L. Ryzhik. Stability in a Nonlinear Population Maturation Model. Mathematical Models and Methods in Applied Sciences (M3AS), 12 (2002), No. 12, 17511772. 
[203] M. Mishima, G. Samimi, A. Kondo, X. Lin, S.B. Howell, The cellular pharmacology of oxaliplatin resistance. Eur. J. Cancer, 38 (2002), No. 10, 1405-1412.

[204] D. Morgan. The Cell Cycle: Principles of Control. Primers in Biology series, Oxford University Press, 2006.

[205] M.-C. Mormont, F. Lévi. Cancer chronotherapy: principles, applications and perspectives. Cancer, 97 (2003), No. 1,155-169.

[206] J.D. Murray. Mathematical biology, 2 vol., 3rd edition, Springer, New York, 2002, 2003.

[207] J.M. Murray. Optimal drug regimens in cancer chemotherapy for single drugs that block progression through the cell cycle. Math. BioSci., 123 (1994), No. 2, 183-193.

[208] I.A. Nestorov, L.J. Aarons, P.A. Arundel, M. Rowland. Lumping of whole-body physiologically based pharmacokinetic models. J Pharmacokinet Biopharm., 26 (1998), No.1, 21-46.

[209] B. Novak, Z. Pataki, A. Ciliberto, J.J. Tyson. Mathematical model of the cell division cycle of fission yeast. Chaos, 11 (2001), No. 1, 277-286.

[210] B. Novak, J.J. Tyson. A model for restriction point control of the cell cycle. J. Theor. Biol., 230 (2004), No. 4, 563-579.

[211] B. Novak, J.J. Tyson. Design principles of biochemical oscillators. Nature Rev. Mol. Cell Biol., 9 (2008), No. 12, 981-991.

[212] T. Oguri, T. Isobe, K. Fujitaka, N. Ishikawa, N. Kohno. Association between expression of the MRP3 gene and exposure to platinum drugs in lung cancer. Int. J. Canc., 93 (2001), No. 4, 584-589.

[213] T. Oguri, Y. Bessho, H. Achiwa, H. Ozasa, K. Maeno, H. Maeda, S. Sato, R. Ueda. MRP8/ABCC11 directly confers resistance to 5-fluorouracil. Mol. Canc. Therap., 6 (2007), No. 1, 122-127.

[214] H. Okamura. Suprachiasmatic nucleus clock time in the mammalian circadian system. Cold Spring Harbor Symposia on quantitative biology, Vol. LXXII (2007), 551-556.

[215] J.M. Pacheco, A. Traulsen, D. Dingli. The allometry of chronic myeloid leukemia. J. Theor. Biol., (2009). [doi:10.1016/j.jtbi.2009.04.003].

[216] J.C. Panetta. A mechanistic model of temozolomide myelosuppression in children with highgrade gliomas. Math. Biosci., 186 (2003), No. 1, 29-41.

[217] B. Perthame. Transport equations in biology. Birkhäuser, Boston, 2007.

[218] B. Perthame, S. Génieys. Concentration in the nonlocal Fisher equation: the HamiltonJacobi limit. Mathematical Modelling of Natural Phenomena, 2 (2007), No.4, 135-151. 
[219] V.K. Piotrovsky. Population pharmacodynamic and pharmacokinetic modeling via mixed effects. Curr. Op. Drug Discov. Devel., 3 (2000), No. 3, 314-319.

[220] Y. Pommier. Topoisomerase I inhibitors: camptothecins and beyond. Nature Rev. Cancer, 6 (2006), No. 10, 789-802.

[221] C.S. Potten, M. Loeffler. Stem cells: attributes, cycles, spirals, pitfalls and uncertainties. Lessons for and from the crypt. Development ,110 (1990), No. 4, 1001-1020.

[222] C.S. Potten, C. Booth, D.M. Pritchard. The intestinal epithelial stem cell: the mucosal governor. Int. J. Exp. Path., 78 (1997), No. 4, 219-243.

[223] L. Preziosi (Ed.). Cancer modelling and simulation. Chapman and Hall / CRC, New York, 2003.

[224] A. Quintas-Cardama, H.M. Kantardjian, J.E. Cortes. Mechanisms of primary and secondary resistance to imatinib in chronic myeloid leukemia. Cancer Control,16 (2009), No. 2, 122-31.

[225] D.A. Rand. Mapping global sensitivity of cellular network dynamics: sensitivity heat maps and a global summation law. J. Roy. Soc. Interface, 5 (2008), Suppl. 1, S59-69.

[226] A. Rafii, et al. Oncologic trogocytosis of an original stromal cell induces chemoresistance of ovarian tumours. PLoS One, 3 (2008), No. 12, e3894, Dec. 2008. [doi:10.1371/journal.pone.0003894].

[227] F.I. Raynaud, et al. In vitro et in vivo pharmacokinetic-pharmacodynamic relationships for the trisubstituted aminopurine cyclin-dependent kinase inhibitors Olomoucine, Bohemine and CYC202. Clin. Canc. Res., 11 (2005), No. 113, 4875-4888.

[228] D.C. Rees, E. Johnson, O. Lewinson. ABC transporters: the power to change. Nature Rev. Mol. Cell Biol., 10 (2009), No. 3, 218-227.

[229] S.M. Reppert, D.R. Weaver. Coordination of circadian timing in mammals. Nature, 418 (2002), No. 6901, 935-941.

[230] B. Ribba, O. Saut, T. Colin, D. Bresch, E. Grenier, J.-P. Boissel. A multiscale mathematical model of avascular tumor growth to investigate the therapeutic benefit of anti-invasive agents. J. Theor. Biol., 243 (2006), No. 4, 532-541.

[231] T. Rich, P.F. Innominato, J. Boerner, M.-C. Mormont, S. Iacobelli, B. Baron, C. Jasmin, F. Lévi. Elevated serum cytokines correlated with altered behavior, serum cortisol rhythm, and dampened 24-hour rest-activity patterns in patients with metastatic colorectal cancer. Clin. Cancer Res., 11 (2005), No. 5, 1757-64.

[232] N.R. Rodrigues, A. Rowan, M.E. Smith, I.B. Kerr, W.F. Bodmer, J.V. Gannon, D.P. Lane. p53 mutations in colorectal cancer. Proc. Natl. Acad. Sci. USA, 87 (1990), No. 19, 7555 7559. 
[233] I. Roeder, M. Loeffler. A novel dynamic model of hematopoietic stem cell organization based on the concept of within-tissue plasticicity. Exp. Hematol., 30 (2002), No. 8, 853-861.

[234] M. Rotenberg. Transport theory for growing cell populations. J. Theor. Biol., 103 (1983), No. 2, 181-199.

[235] P. Ruoff, S. Mohsenzadeh, L. Rensing. Circadian rhythms and protein turnover: the effect of temperature on the period lengths of clock mutants simulated by the Goodwin oscillator. Naturwissenschaften, 83 (1996), No. 11, 514-7.

[236] P. Ruoff, M. Vinsjevik, C. Monnerjahn, L. Rensing. The Goodwin model: simulating the effect of light pulses on the circadian sporulation rhythm of Neurospora crassa. J. Theor. Biol., 209 (2001), No. 1, 29-42.

[237] A. Sakaue-Sawano, H. Kurokawa, T. Morimura, A. Hanyu, H. Hama, H. Osawa, S. Kashiwagi, K. Fukami, T. Miyata, H. Miyoshi, T. Imamura, M. Ogawa, H. Masai, A. Miyawaki. Visualizing spatiotemporal dynamics of multicellular cell-cycle progression. Cell, 32 (2008), No. 3, 487-98.

[238] A. Sakaue-Sawano, K. Ohtawa, H. Hama, M. Kawano, M. Ogawa, A. Miyawaki. Tracing the silhouette of individual cells in S/G2/M phases with fluorescence. Chem Biol., 15 (2008), No. $12,1243-8$.

[239] U. Schibler. Liver regeneration clocks on. Science, 302 (2003), No. 5642, 234-235.

[240] D. Schiffer. Radiotherapy by particle beams (hadrontherapy) of intracranial tumours: a survey on pathology. Neurol. Sci., 26 (2005), No. 1, 5-12.

[241] R.L. Schilsky, G.M. Milano, M.J. Ratain (Eds.). Principles of Antineoplastic Drug Development and Pharmacology. Marcel Dekker, New York, 1996.

[242] L.B. Sheiner, J.-L. Steimer. Pharmacokinetic/pharmacodynamic modeling in drug development. Annu. Rev. Pharmacol. Toxicol., 40 (2000), 67-95.

[243] J.A. Sherratt, M.A. Chaplain. A new mathematical model for avascular tumour growth. J. Math. Biol., 43 (2001), No. 4, 291-312.

[244] Y. Shiloh. ATM and related kinases: Safeguarding genome integrity. Nature Rev. Cancer, 3 (2003), No. 3,155-168, 2003.

[245] M. Simeoni, P. Magni P, C. Cammia, G. De Nicolao, V. Croci, E. Pesenti, M. Germani, I. Poggesi, M. Rocchetti. Predictive pharmacokinetic-pharmacodynamic modeling of tumor growth kinetics in xenograft models after administration of anticancer agents. Cancer Res., 64 (2004), No. 3, 1094-1101. 
[246] R. Smaaland, O.D. Laerum, K. Lote, O. Sletvold, R.B. Sothern, R. Bjerknes. DNA Synthesis in Human Bone Marrow is Circadian Stage Dependent. Blood, 77 (1991), No. 12, 26032611.

[247] C. Sonnenschein, A.M. Soto. Carcinogenesis and metastasis now in the third dimension What's in it for pathologists? Am. J. Pathol., 168 (2006), No. 2, 363-366.

[248] C. Sonnenschein, A.M. Soto. Theories of carcinogenesis: an emerging perspective. Seminars in cancer biology, 18 (2008), No. 5, 372-377.

[249] A.M. Soto, C. Sonnenschein. The somatic mutation theory of cancer: growing problems with the paradigm? BioEssays, 26 (2004), No. 10, 1097-1107.

[250] A.M. Soto, C. Sonnenschein, P.A. Miquel. On physicalism and downward causation in developmental and cancer biology. Acta biotheor., 56 (2008), No. 4, 257-74.

[251] F.X. Su, X.Q. Hu, W.J. Jia, C. Gong, E.W. Song, P. Hamar. Glutathion S Transferase $\pi$ indicates chemotherapy resistance in breast cancer. J. Surg. Res., 113 (2003), No. 1, 102108.

[252] G.W. Swan, T.L. Vincent. Optimal control analysis in the chemotherapy of IgG multiple myeloma. Bull. Math. Biol., 39 (1977), No. 3, 317-337.

[253] G.W. Swan. Applications of optimal control theory in biomedicine. Marcel Dekker, New York, 1984.

[254] K.R. Swanson, E.C. Alvord Jr, J.D. Murray. A quantitative model for differential motility of gliomas in grey and white matter. Cell Prolif., 33 (2000), No. 5, 317-29.

[255] K.R. Swanson, C. Bridge, J.D. Murray, E.C. Alvord Jr. Virtual and real brain tumors: using mathematical modeling to quantify glioma growth and invasion. J Neurol. Sci., 16 (2003), No. 1, 1-10.

[256] R. Tang, A.M. Faussat, J.-Y. Perrot, Z. Marjanovic, S. Cohen, T. Storme, H. Morjani, O. Legrand, J.-P. Marie. Zosuquidar restores drug sensitivity in P-glycoprotein expressing acute myeloid leukemia (AML). BMC Cancer, 8 (2008), 51. [doi:10.1186/1471-2407-8-51].

[257] T.N. Tozer, M. Rowland. Introduction to Pharmacokinetics and Pharmacodynamics: The Quantitative Basis of Drug Therapy. Lippincott, Philadelphia, 2006.

[258] Y. Tsukamoto, Y. Kato, M. Ura, I. Horii, T. Ishikawa, H. Ishitsuka, Y. Sugiyama. Investigation of 5-FU disposition after oral administration of capecitabine, a triple-prodrug of 5-FU, using a physiologically based pharmacokinetic model in a human cancer xenograft model: comparison of the simulated 5-FU exposures in the tumour tissue between human and xenograft model. Biopharm Drug Dispos., 22 (2001), No. 1, 1-14. 
[259] J.J. Tyson, C.I. Hong, C.D. Thron, B. Novak. A simple model of circadian rhythms based on dimerization and proteolysis of PER and TIM. Biophys J.,77 (1999), No. 5, 2411-7.

[260] J.J. Tyson, K. Chen, B. Novak. Network dynamics and cell physiology. Nature Rev. Mol. Cell Biol., 2 (2001), No. 12, 908-916.

[261] P. Ubezio. Unraveling the complexity of cell cycle effects of anticancer drugs in cell populations. Disc. Cont. Dyn. Syst. B, 4 (2004), No. 1, 323-335.

[262] K. Vanselow, J.T. Vanselow, P.O. Westermark, S. Reischl, B. Maier, T. Korte, A. Herrmann, H. Herzel, A. Schlosser, A. Kramer. Differential effects of PER2 phosphorylation: molecular basis for the human familial advanced sleep phase syndrome (FASPS). Genes Dev., 20 (2006), No. 19, 2660-2672.

[263] J. Viguier, et al. ERCC1 codon 118 polymorphism is a predictive factor for the tumor response to oxaliplatin/5-fluorouracil combination chemotherapy in patients with advanced colorectal cancer. Clin Cancer Res., 11 (2005), No. 17, 6212-7.

[264] B. Vogelstein, D. Lane, A.J. Levine. Surfing the p53 network. Nature, 408 (2010), No. 6810 , 307-310.

[265] H.M. Warenius, L. Seabra, L. Kyritsi, R. White, R. Dormer, S. Anandappa, C. Thomas, A. Howarth. Theranostic proteomic profiling of cyclins, cyclin dependent kinases and Ras in human cancer cell lines is dependent on p53 mutational status. Int. J. Oncol., 32 (2008), No. 4, 895-907.

[266] F.M. Watt, B.L. Hogan. Out of Eden: stem cells and their niches. Science, 287 (2000), No. 5457, 1427-1430.

[267] G.F. Webb. Resonance phenomena in cell population chemotherapy models. Rocky Mountain J. Math., 20 (1990), No. 4, 1195-1216.

[268] R.A. Weinberg. One renegade cell: how cancer begins. Basic Books, New York, 1998.

[269] H.V. Westerhoff, B.O. Palsson. The evolution of molecular biology into systems biology. Nature Biotechnol., 22 (2004), No. 10, 1249-1252.

[270] H.V. Westerhoff. Mathematical and theoretical biology for systems biology, and then. . . vice versa. J. Math. Biol., 54 (2007), No. 1, 147-150.

[271] World Health Organisation (WHO). Preventing chronic diseases: a vital investment. (20055), Source: http://www.who.int/chp/chronic_disease_report/full_report.pdf 2005

[272] D. Wodarz, D. Killer Cell Dynamics. Springer, New York, 2007.

[273] M.W. Wu, L.J. Xian, X.M. Li, P. Innominato, F. Lévi. Circadian expression of dihydropyrimidine dehydrogenase, thymidylate synthase, c-myc and p53 mRNA in mouse liver tissue. Ai Zheng (Chinese Journal of Cancer), 23 (2004), No. 3, 235-242. 
[274] C. Wyman, R. Kanaar. DNA double-strand break repair: All's well that ends well. Annu. Rev. Genet., 40 (2006), 363-383.

[275] J.H. Xing, J. Chen. The Goldbeter-Koshland switch in the first-order region and its response to dynamic disorder. PLoS ONE, 2008 May 14;3(5):e2140. [doi:10.1371/journal.pone.0002140].

[276] S. Yamaguchi, H. Isejima, T. Matsuo, R. Okura, K. Yagita, M. Kobayashi, H. Okamura. Synchronization of cellular clocks in the suprachiasmatic nucleus. Science, 302 (2003), No. 5649, 1408-12.

[277] S. You, P.A. Wood, Y. Xiong, M. Kobayashi, J. Du Quiton, W.J.M. Hrushesky. Daily coordination of cancer growth and circadian clock gene expression. Breast Canc. Res. Treatment, 91 (2005), No. 1, 47-60.

[278] J. Zamborsky, C.I. Hong, A. Csikasz-Nagy. Computational analysis of mammalian cell division gated by a circadian clock: quantized cell cycles and cell size control. J. Biol. Rhythms, 22 (2007), 542-553.

[279] A. Zetterberg, O. Larsson, K.G. Wiman. What is the restriction point? Curr. Opin. Cell Biol., 7 (1995), No. 6, 835-42.

[280] L. Zitvogel, A. Tesniere, G. Kroemer. Cancer despite immunosurveillance: immunoselection and immunosubversion. Nature Rev. Immunol., 6 (2006), No. 10, 715-727.

[281] L. Zitvogel, L. Apetoh, F. Ghiringhelli, G. Kroemer. Immunological aspects of cancer chemotherapy. Nature Rev. Immunol., 8 (2008), No. 1, 59-73.

[282] L. Zitvogel, L. Apetoh, F. Ghiringhelli, F. André, A. Tesniere, G. Kroemer. The anticancer immune response: indispensable for therapeutic success? J. Clin. Invest., 118 (2008), No. 6, 1991-2001. 